\title{
Política Monetária, Macroprudencial e Bancos: Evidências Empíricas usando VAR em Painel
}

\author{
(Monetary and Macroprudential Policies and Banks: Empirical \\ Evidences from Panel-VAR)
}

\author{
Fernando da Silva Vinhado * \\ José Angelo Divino **
}

\begin{abstract}
Resumo
O objetivo desse artigo é investigar as relações entre as políticas monetárias e macroprudenciais e o setor bancário da economia brasileira, explorando a estrutura cross-section como fonte de inter-relações entre aspectos sistêmicos daquelas políticas e o comportamento dos bancos. Funções impulso-respostas são computadas por estimações VAR em painel para 56 instituições que atuaram no mercado bancário brasileiro entre 2001 e 2013. Dentre os resultados, pode-se destacar a influência das políticas monetária e macroprudencial sobre os níveis de exposição a riscos financeiros, capital e estabilidade financeira dos bancos. Há uma complementaridade entre os instrumentos daquelas políticas e a estabilização da inflação. As relações envolvendo métricas bancárias revelam preferência por liquidez em contextos de maior risco, indícios de uma estrutura bancária competitiva e a formação de buffers de capital que favorecem a
\end{abstract}

Submetido em 03 de junho de 2015. Reformulado em 18 de dezembro de 2015 Aceito em 18 de dezembro de 2015. Publicado on-line em 25 de janeiro de 2016. O artigo foi avaliado segundo o processo de duplo anonimato além de ser avaliado pelo editor. Editor responsável: Márcio Laurini.

Doutorando do Programa de Pós-Graduação em Economia da Universidade Católica de Brasília - PPGE/UCB e Pesquisador na Diretoria de Gestão de Riscos do Banco do Brasil S.A, Brasília, DF, Brasil. E-mail: fernando.vinhado@ catolica.edu.br.

*** Professor e Pesquisador do Programa de Pós-Graduação em Economia da Universidade Católica de Brasília - PPGE/UCB, Brasília, DF, Brasil. E-mail: jangelo@ucb.br.

Este artigo não reflete a opinião do Banco do Brasil S.A e/ou dos seus membros. Os autores agradecem a dois pareceristas anônimos pelos comentários e sugestões. Pelo apoio financeiro, Fernando da Silva Vinhado agradece à CAPES e José Angelo Divino agradece ao CNPq.

Rev. Bras. Finanças (Online), Rio de Janeiro, Vol. 13, No. 4, October 2015, pp. 691-730 ISSN 1679-0731, ISSN online 1984-5146

(C2015 Sociedade Brasileira de Finanças, under a Creative Commons Attribution 3.0 license http://creativecommons.org/licenses/by/3.0 
estabilidade financeira. Isso ratifica a importância da exigência de capital como instrumento para manutenção de um sistema financeiro estável.

Palavras-chave: política monetária; política macroprudencial; bancos; VAR em painel.

Códigos JEL: E44; G21; G28.

\begin{abstract}
The objective of this paper is to investigate the relationship between monetary and macroprudential policies and the banking sector of the Brazilian economy, exploiting its cross-section structure as a source of interrelations between systemic aspects of those policies and the behavior of banks. Impulse-response functions are computed from the estimation of panel-VAR for 56 institutions that were active in the Brazilian banking sector between 2001 and 2013. Among the results, we can highlight the influence of monetary and macroprudential policies on levels of exposure to financial risk, capital and financial stability of banks. There is a complementarity between the instruments of those policies and the stabilization of inflation. The relationships involving banking metrics reveal preference for liquidity in contexts of higher risks, evidence of a competitive banking structure, and formation of capital buffer that lead to financial stability. This confirms the importance of capital requirements as a tool to maintain a stable financial system.
\end{abstract}

Keywords: monetary policy; macroprudential policy; banks; panel-VAR.

\title{
1. Introdução
}

Bancos são instituições complexas, compreendidas tanto como intermediários financeiros como criadores de meios de pagamento que irrigam de liquidez a economia. Dessa forma, são percebidos como instituições com comportamento decisivo capaz de influenciar o nível de gastos dos agentes e, consequentemente, as variáveis reais da economia.

Ainda sob o aspecto macroeconômico, a moderna teoria monetária enfatiza o papel da taxa básica de juros como o principal instrumento de política monetária, sendo que uma parcela da transmissão dessa política ao setor real da economia ocorre via canal do crédito bancário. Dessa forma, os bancos assumem uma posição central para essa dinâmica, uma vez que são instituições ofertantes do maior volume de crédito na economia, tanto aos indivíduos quanto às firmas. Taylor (1995) foi o pioneiro a identificar o uso da taxa de juros como o principal instrumento da política monetária. 
Adicionalmente, conforme aponta Galati \& Moessner (2011), tem-se o papel da autoridade regulatória que busca evitar riscos sistêmicos e custos de uma crise, bem como controlar expansões excessivas mediante intervenções para manutenção da estabilidade da oferta de crédito, suavização de ciclos e contenção de bolhas especulativas. Tal papel, especialmente após a crise americana do subprime, vem sendo realizado por meio do desenvolvimento de um arcabouço regulatório denominado política macroprudencial. $\mathrm{O}$ uso de requerimentos de reservas sobre depósitos bancários, como destaca Tovar et al. (2012), assim como as ações de Basiléia, especialmente via definição de níveis mínimos de capital, são os principais exemplos de política macroprudencial atualmente em uso no Brasil.

Cecchetti \& Kohler (2012) destacam o grau de relacionamento entre as políticas monetária e macroprudencial, ressaltando que elas não devem ser vistas isoladamente devido a elementos comuns que afetam o canal bancário por meio da concessão de crédito. Há uma complementariedade entre medidas monetárias e macroprudenciais, cujos efeitos sobre o lado real da economia devem ser tomados conjuntamente considerando o canal do crédito como um dos mecanismos de transmissão.

Nesse contexto, em que não se pode negar a influência dessas decisões monetárias e regulatórias no cotidiano das instituições financeiras, ressalta-se que os bancos, sob uma perspectiva microeconômica, exercem suas atividades empresariais como firmas que buscam a otimização racional dos seus lucros. A gestão e o desempenho microeconômico dos bancos, que envolvem basicamente perspectivas de liquidez, solvência, exposição a riscos e geração de resultados, são fortemente influenciados pelas orientações das políticas monetária e macroprudencial.

Hirtle \& Lopes (1999) consideram que as principais métricas para expressar o desempenho microeconômico dos bancos estão contidas na metodologia CAMELS, utilizada na definição de ratings entre instituições financeiras por órgãos de supervisão bancária. Essa sigla deriva dos aspectos definidos como chave no desempenho dos bancos, quais sejam: Capital adequacy (C), Asset quality (A), Management (M), Earnings (E), Liquidity (L) e Sensitivity to market risk (S).

Diante da intensiva utilização, relevância e impacto das medidas de políticas monetárias e macroprudenciais sobre a atividade bancária, temse como problema de pesquisa saber como e em que intensidade choques exógenos nessas políticas são transmitidos para o setor bancário da 
economia. Logo, o objetivo central do presente artigo é explorar as relações empíricas entre as políticas monetária e macroprudencial e o segmento bancário do sistema financeiro da economia brasileira.

A investigação é conduzida por meio da aplicação de um Vetor Autorregressivo a dados organizados em painel (PanelVAR) para 56 instituições que atuaram no mercado bancário brasileiro entre $2001 \mathrm{e}$ 2013. Espera-se que a estrutura em cross-section do segmento bancário revele inter-relações entre aspectos sistêmicos das políticas monetária e macroprudencial e o comportamento individual dos bancos.

Os principais resultados sugerem que as elevações na taxa básica de juros e no requerimento compulsório ampliam o nível de exposição dos bancos a riscos financeiros, na adequação do capital e na estabilidade financeira, provocando efeitos conflitantes para o Banco Central em termos de busca por estabilidade monetária ou estabilidade financeira.

Foram, também, encontradas evidências de complementaridade entre as políticas monetária e macroprudencial, com o uso do requerimento de reservas compulsórias como instrumento de controle do nível de preços. Esse resultado está de acordo com as evidências obtidas por Kornelius e Divino (2011) acerca da combinação adequada entre a regra de juros e a política de requerimento de compulsório para o controle da inflação.

O histórico de prática de preferência por liquidez em contexto de maior risco, traços de competitividade no mercado bancário brasileiro e indícios que sugerem como a formação de níveis mínimos de capital favorecem a estabilidade e solidez do sistema financeiro também foram observados na evidência empírica.

Esses resultados contribuem com a literatura ao ampliar a compreensão sobre o funcionamento do mercado financeiro brasileiro, oferecendo subsídios para orientar tanto a gestão nas organizações bancárias como a regulação do ambiente financeiro.

O restante do artigo está organizado conforme se segue. Na seção 2 é apresentada literatura relacionada. A seção 3 discute a metodologia empírica, abordando tanto a formulação empírica propriamente dita como a modelagem econométrica utilizada. Na seção 4 são descritos os dados e apresentados e analisados os resultados obtidos. Por fim, a seção 5 é dedicada às observações conclusivas.

\section{Revisão da literatura}


Um arcabouço teórico e empírico relacionado à discussão proposta neste trabalho é apresentado, começando pela discussão sobre a transmissão das políticas monetária e macroprudencial e seus efeitos sobre a atividade bancária. Na sequência, procura-se elucidar como as políticas estão associadas entre si.

\subsection{Transmissão da política monetária para a atividade bancária}

Os tradicionais mecanismos de transmissão da política monetária, segundo Mishkin (1996) e Taylor (1995), envolvem, entre outros, o canal dos juros e do crédito, com efeitos diretos sobre os volumes de depósitos e a concessão de crédito pelas instituições financeiras.

Ramos-Tallada (2015) ao discutir a transmissão da política monetária pelo crédito, ressalta a sensibilidade da política, usualmente avaliada por elevações na taxa de juros, em relação a características bancárias que envolvem incerteza, riscos e liquidez. Ilustra, dessa forma, a interação e também potenciais efeitos da política monetária sobre diferentes elementos da atividade bancária.

O autor enfatiza essa condição, destacando que a literatura empírica aborda variáveis relacionadas à estrutura financeira dos bancos, como liquidez e índice de capitalização, e concluindo que os bancos enfrentam riscos a partir de choques monetários. Isso contrapõe às evidências empíricas de Distinguin et al. (2013) que, ao estudar a relação entre a liquidez e o capital dos bancos na Europa e Estados Unidos, não encontram indícios que a política monetária via taxas de juros exerce influência relevante para explicar a liquidez bancária.

Nesse contexto, Chmielewski (2005) argumenta que o grau de aversão a riscos dos bancos e o impacto das taxas de juros sobre o risco de default também estreitam o canal de política monetária. Complementarmente, Altunbas et al. (2010) consideram que quanto maior o grau de exposição do banco ao risco de crédito, menor é a restrição da oferta de crédito do banco frente a um choque na política monetária.

Agur \& Demertzis (2012) dão ênfase também a potenciais efeitos da transmissão da política monetária sobre os riscos, argumentando que o aumento nos juros provoca efeito no custo de captação dos bancos, exigência de um maior prêmio de risco por parte dos debt holders, aumento dos custos passivos e potenciais reflexos sobre a exposição e 
volatilidade na composição dos ativos. Defendem que esse efeito encadeia menor rentabilidade e maior ineficiência à atividade bancária.

Para Delis \& Karavias (2015), existe um nível ótimo de risco de crédito que maximiza o lucro dos bancos, sendo que políticas monetárias expansionistas ou contracionistas, em períodos de estabilidade, distanciam o nível de assunção de riscos de crédito das instituições do ponto ótimo que potencializa a geração de lucros.

Sob uma perspectiva de risco de mercado, Kerstein \& Kozberg (2013) destacam que, dada a configuração dos ativos e passivos dos bancos, tanto em termos de período de vencimento quanto de natureza das taxas contratadas, alterações na taxa de juros provocam distorções momentâneas com pressões sobre os spreads e lucros dos bancos.

Van den Heuvel (2006) dispensa atenção ao fato de que o aumento na taxa de juros de curto prazo corrói os recursos próprios dos bancos, haja vista os desequilíbrios existentes no balanço das instituições. Para o autor, esse efeito encoraja os bancos a reduzirem sua oferta de crédito como forma menos onerosa comparativamente a aumentos de capital, dada a necessidade de manutenção de limites regulatórios.

O efeito da política monetária sobre o capital bancário também é abordado por Tabak et al. (2011), que relacionam os efeitos de uma política monetária restritiva com excesso de capital nos bancos e formação de buffers. Argumentam que aumentos nos juros afetam negativamente a oferta de crédito, com consequente redução na exigência de capital regulatório.

Lambert \& Ueda (2014) discutem o efeito de uma política monetária não convencional sobre os bancos e destacam que, nesse contexto, pode existir um efeito positivo sobre o custo de captação quando as taxas estão próximas de zero, afetando a rentabilidade dos bancos. Entretanto, pode surgir uma estrutura achatada na rentabilidade das operações ativas de longo prazo contratadas com taxas variáveis que, confrontadas com captações de renda fixa, podem comprometer as margens financeiras no curto prazo. Nesse caso, alterações nos volumes de empréstimos e novas fontes de rendas como tarifas são apontadas como ações típicas de compensação.

Sob a ótica do risco, os autores consideram também que as baixas taxas de juros associadas a menor volatilidade nos preços dos ativos encorajam os bancos a reduzir as posições de menor risco, com 
realocações em aplicações de risco mais elevado que afetam a estrutura de capital.

A literatura macroeconômica sob equilíbrio geral que contempla fricções financeiras também tem oferecido avanços que vem permitindo melhor compreender a transmissão da política monetária sobre a atividade bancária. Gerali et al. (2010), por exemplo, investigam os mecanismos de transmissão de impulsos monetários e no capital bancário em países europeus. As evidências empíricas indicam que um choque de política monetária via taxa básica de juros é transmitido rapidamente para as taxas financeiras dos bancos, levando a retração das operações de crédito e captação, com impacto de curto prazo favorável aos spreads, lucros e nível de capital bancário, mas com reversão gradual após alguns trimestres.

Também para países da zona do Euro, Pariès et al. (2011), ao analisarem o papel das fricções financeiras na economia antes da crise do subprime, discutem o tempo de ajuste das taxas de empréstimos após alterações na taxa de política e destacam a maior persistência das taxas no mercado de varejo. Concluem que os choques na política monetária afetam negativamente a oferta de crédito e, apesar de favorecem os spreads, sacrificam em um primeiro momento os lucros dos bancos com consequente impacto indesejado sobre a capacidade de acumulação de capital bancário.

Para a economia brasileira, Carvalho et al. (2013) avaliam os canais de transmissão dos juros, compulsório e requerimentos de capital. Dentre os resultados, mostram que o aumento na taxa básica de juros influencia negativamente nos volumes de crédito e captação dos bancos, com aumento na inadimplência, liquidez e buffers de capital dos bancos.

\subsection{Transmissão da política macroprudencial para a atividade bancária}

A ênfase dada na literatura sobre a política macroprudencial, em geral, envolve a manutenção da estabilidade financeira e a resiliência do setor financeiro de forma a mitigar riscos sistêmicos associados à excessiva alavancagem financeira, sinais de bolhas especulativas e flutuações adversas no ambiente econômico.

Pode-se relatar também, conforme Kregel (2010) e Tymoigne (2010) descrevem, os problemas de supervisão existentes até a crise do subprime de 2008, caracterizados por uma estrutura microprudencial focada em 
condições de solvência dos agentes individualmente e sua reformulação a partir daquela crise, agregando um caráter sistêmico.

Conforme Basto (2013), os instrumentos macroprudenciais podem ser agrupados em três categorias: (I) - limitações à concentração de ativos ou ao crescimento do crédito; (II) - requisitos de capital ou de liquidez; e, (III) - critérios de elegibilidade ao crédito. Enquanto esse último visa condicionar mais diretamente o comportamento dos devedores, os dois primeiros exercem influência direta sobre o comportamento das instituições financeiras.

Montoro e Moreno (2011) destacam a exigência do recolhimento compulsório sobre os depósitos bancários como importante instrumento de política macroprudencial capaz de contribuir para a estabilidade financeira à medida que suaviza flutuações de liquidez durante o ciclo econômico. Mazzucco \& Meurer (2014) ratificam essa perspectiva do uso do compulsório em finalidades não monetárias, enquanto Tovar et al. (2012) destacam, ainda, a sua maior utilização em países da América Latina e economias emergentes para promover movimentos contra cíclicos sobre a oferta de crédito dos bancos.

A maior exigência de reservas compulsórias sobre depósitos, para Ramos-Tallada (2015), gera custos adicionais de captação aos bancos por causa do impacto sobre a liquidez das instituições bancárias. Nesse sentido, o efeito líquido é uma redução na oferta de crédito.

Kornelius \& Divino (2011), em uma abordagem de equilíbrio geral com fricções financeiras, associam os efeitos do compulsório à oferta de crédito dos bancos. Caso o compulsório seja remunerado a uma taxa inferior ao retorno dos depósitos, um aumento no requerimento incentiva os bancos a reduzirem seu volume de crédito e a aumentarem seu capital próprio, diminuindo, consequentemente, sua alavancagem. Isso permite, também, o uso do recolhimento compulsório como instrumento de política macroprudencial.

Carvalho et al. (2013) também identificam a transmissão do aumento no requerimento de reservas sobre os custos de captação e taxas de empréstimos dos bancos na economia brasileira. Os efeitos apontados envolveram, ainda, redução na oferta de crédito, queda na liquidez dos bancos e aumento no capital bancário.

Também consideradas como instrumentos de política macroprudencial são as ações de Basiléia que visam fortalecer a regulação, a supervisão e o gerenciamento de riscos no setor bancário, 
especialmente via construção de níveis mínimos de capital, tanto para moderar expansões de crédito quanto para suportar perdas inesperadas em períodos de estresse econômico (BASEL COMITTEE ON BANKING SUPERVISION, 2010a e 2010b).

Para Basto (2013), a transmissão deste instrumento de requisito de capital depende, em grande parte, da atuação dos bancos para fazer face aos requisitos regulamentares. Pois, nesse caso de maior exigência de capital, os efeitos se materializam mediante aumento no capital social e/ou redução e recomposição dos ativos. No caso da opção por aumento de capital, a transmissão vai envolver um custo maior de captação, com efeito transferido para as condições de concessão de crédito. Já no caso de decisões sobre o portfólio ativo, o efeito esperado é direto sobre a quantidade ofertada de crédito.

Gerali et al. (2010) identificaram para o mercado Europeu que choques que expressem maior exigência no capital bancário, dada inclusive por uma nova orientação macroprudencial, elevam os custos de capital, provocando efeitos imediatos sobre as taxas financeiras praticadas pelos bancos, redução na oferta de crédito e aumento imediato nos spreads e lucros, com maior tempo de reversão comparativamente ao choque de política monetária.

$\mathrm{Na}$ mesma linha, os resultados de Carvalho et al. (2013) para a economia brasileira também sinalizam o efeito do aumento no requerimento de capital sobre a menor oferta de crédito pelos bancos, majoração de taxas de operações ativas, além dos reflexos em termos de constituição de maiores buffers de liquidez e redução na exposição a risco de crédito.

Pariès et al. (2011), entretanto, encontram resultado diferente, sugerindo que choques no capital sacrificam a geração de lucro das instituições no curto prazo, mesmo com os estímulos favoráveis sobre as margens dos empréstimos, haja vista a queda no volume dos empréstimos.

\subsection{Interação entre políticas monetária e macroprudencial}

Em que pese as diferentes finalidades das políticas monetária e macroprudencial, respectivamente em termos de estabilidade monetária e financeira, não se pode negar, conforme destaca Cecchetti \& Kohler (2012), a complementaridade da política macroprudencial à política 
monetária. Há uma substitutibilidade e similaridade de efeitos em relação ao mecanismo de transmissão no que tange o canal do crédito bancário.

Cecchetti \& Kohler (2012) consideram ser necessária uma coordenação apropriada entre as políticas e apontam que alterações nesses instrumentos influenciam os custos de captação dos bancos, com impacto sobre as taxas e spreads praticados, bem como sobre os volumes de captação, crédito, adequação do capital e nível de exposição a riscos. Evidências encontradas por Pariès et al. (2011) e Tovar et al. (2012) também ratificam esse aspecto de complementaridade entre política monetária e macroprudencial.

Enquanto os resultados de Pariès et al. (2011) envolvem os efeitos dos choques na taxa de juros e no requerimento de capital sobre a oferta de crédito, Tovar et al. (2012) destacam que os requerimentos de reserva sobre depósitos bancários promovem movimento contra cíclico sobre o crédito e liquidez, complementando a política monetária. As reservas compulsórias sobre depósitos complementam também os requerimentos de capital quando a avaliação dos ativos está sujeita a maiores incertezas.

\section{Metodologia}

\subsection{Modelo Empírico}

A modelagem empírica consiste da estimação de vetores autorregressivos para dados organizados em painel (PanelVAR). A escolha dessa técnica justifica-se pela estrutura dos microdados bancários, que estão disponíveis para diversas instituições financeiras ao longo de um razoável horizonte temporal. A aplicação da metodologia de PanelVAR permite que se combine o tratamento endógeno das variáveis envolvidas na estimação com a modelagem da heterogeneidade individual não observada e específica a cada instituição financeira presente na amostra por meio de efeitos fixos. Além disso, essa técnica possibilita a estimação de funções impulso-respostas ortogonalizadas, em que se identificam as respostas de variáveis endógenas a choques estruturais de interesse oriundos na política monetária, política macroprudencial ou no próprio setor bancário.

A estimação do VAR em painel segue a abordagem de Love \& Zicchino (2006), combinando a lógica de se considerar as variáveis como endógenas em um sistema com as propriedades de um painel de dados. Assim, contornam-se os problemas de simultaneidade e de heterogeneidade individual não observada. 
Nesse caso, um PanelVAR de ordem $j$ pode ser representado na sua forma padrão como:

$$
Z_{i, t}=\Gamma_{0}+\Gamma_{1} Z_{i, t-j}+f_{i}+\varepsilon_{i, t}
$$

onde:

$$
\begin{gathered}
Z_{i, t}=\left\{W_{t}, X_{i, t}, C_{t}^{1}, C_{i, t}^{2}\right\} ; \\
Z_{i, t-j}=\left\{W_{t-j}, X_{i, t-j}, C_{t-j}^{1}, C_{i, t-j}^{2}\right\}, \operatorname{com} j=1,2, \ldots, p ;
\end{gathered}
$$

$W=\{$ Over selic, taxa de recolhimento compulsório $\}$

$X=\{$ Risco de crédito, risco de mercado, liquidez, lucro, índice de Basiléia $\}$.

$C^{1}=\{$ Variáveis de controle variantes no tempo $\} ;$

$C^{2}=\{$ Variáveis de controle variantes no tempo e entre indivíduos $\} ;$

$Z_{i, t}$ e $Z_{i, t-j}$ representam conjuntos de vetores compostos por variáveis endógenas, $f_{i}$ é o efeito fixo não observado e $\varepsilon_{i, t}$ define o termo de erro aleatório.

$\mathrm{O}$ vetor $W$ é constituído por séries variantes exclusivamente no tempo, sendo composto pelos instrumentos das políticas monetária e macroprudencial. No vetor $X$ estão reunidos os dados organizados em painel e que expressam a performance dos bancos, tendo como base a metodologia $C A M E L S^{1}$. Nesse caso, a dimensão Capital adequacy (C) da metodologia é dada pelo Indice de Basiléia, Asset quality (A) pelo Risco de Crédito, Earnings (E) pelo Lucro, Liquidity (L) pela Liquidez e Sensitivity to market risk (S) pelo Risco de Mercado.

$C^{1}$ e $C^{2}$ são controles incluídos nas estimações com o intuito de se evitar problemas de especificação e assegurar maior qualidade às estimações. Os controles variantes exclusivamente no tempo, $C^{1}$, compreendem a especificação padrão e são compostos por uma variável dummy que modela a mudança de tendência na taxa Over Selic a partir de 2003 e a taxa de inflação medida pelo IPCA. Nesse caso, destaca-se que a inflação do IPCA, além de figurar como variável base do regime de metas de inflação, também capta inter-relações existentes com

\footnotetext{
${ }^{1}$ Dentre as métricas consideradas pela metodologia CAMELS como fundamentais para o desempenho das instituições financeiras (capital adequacy, asset quality, management, earnings, liquidity e sensitivity to market risk), no presente estudo só não é contemplada a capacidade gerencial dos administradores, dada subjetividade envolvida e dificuldade na obtenção de informações.
} 
o ciclo econômico. Por sua vez, $C^{2}$ envolve variável de controle que é testada em especificações alternativas e utilizada tradicionalmente na literatura como medida de solvência bancária, considerando de forma agregada o grau de capitação e risco do banco com a geração e qualidade dos retornos produzidos ao longo do tempo.

A abordagem teórica da estimação de VAR em painel foi discutida por Holtz-Eakin et al. (1988), que propõem métodos alternativos de estimação, formas de identificação e testes de hipóteses. Além disso, discutem as propriedades assintóticas dos estimadores por GMM. Love \& Zicchino (2006) realizam uma aplicação de VAR em painel para estudar as relações dinâmicas entre condições financeiras e o nível de investimento das firmas. Acabam, também, por aprofundar a discussão metodológica sobre VAR em painel, especialmente no que concerne à estimação de funções impulso-respostas.

A presença de efeitos fixos não observados, $f_{i}$, contempla o fato de que a estrutura do VAR não é a mesma entre as unidades de corte seccional. Como $f_{i}$ é correlacionado com as variáveis dependentes defasadas em painel do VAR, deve-se aplicar um estimador apropriado, que elimine aquela correlação sem gerar nenhum viés de estimação. Love \& Zicchino (2006) propõem que seja utilizada a transformação de Helmert, descrita em Arellano e Bover (1995). Essa transformação remove os efeitos fixos preservando a ortogonalidade entre as variáveis transformadas e os regressores defasados, que podem ser usados com variáveis instrumentais no estimador GMM por sistema (system GMM). Considerando $Z_{i, t}$ o vetor de variáveis endógenas do modelo e seguindo Arellano e Bover (1995), a transformação de Helmert pode ser descrita como:

$$
Z_{i, t}^{*}=Y_{t}\left\{Z_{i, t}-\left(\frac{1}{T-t}\right)\left(Z_{i,(t+1)}+\cdots+Z_{i, T}\right)\right\}, \quad t=1, \ldots, T-1,
$$

onde:

$$
r_{t}^{2}=(T-t) /(T-t+1)
$$

Dessa forma, para cada uma das primeiras $(T-1)$ observações, subtrai-se a média das observações futuras restantes na amostra. $\mathrm{O}$ peso $Y_{t}$ é introduzido para equalizar as variâncias. Arellano \& Bover (1995) mostram como construir um operador ortogonal de desvios para frente que produz essa transformação quando aplicado às variáveis do VAR em painel. 
Com isso, elimina-se o viés provocado pela correlação entre a heterogeneidade não observada, $f_{i}$, e os regressores defasados, assegurando a ortogonalidade entre as variáveis transformadas e aqueles regressores bem como a consistência das estimações via GMM.

\subsection{Procedimentos de identificação}

Para o cálculo das funções de impulso respostas, é necessário que os resíduos estruturais ortogonais sejam identificados. Como a matriz de variância-covariância dos erros não é diagonal e os erros do VAR reduzido apresentam relações contemporâneas entre si, devem-se decompor os erros para que se tornem ortogonais. Para tanto, será adotado procedimento de identificação de Choleski, em que se adota um ordenamento particular das variáveis do sistema. Nesse caso, o ordenamento toma as variáveis que aparecem inicialmente no sistema como fracamente exógenas, enquanto aquelas que estão dispostas na sequência são consideradas como mais endógenas.

O ordenamento da especificação base proposta é dado por: IPCA $\rightarrow$ Selic $\rightarrow$ Compulsório $\rightarrow R \_C r e ́ d i t o ~ \rightarrow R \_M e r c a d o \rightarrow$ Liquidez $\rightarrow$ Lucro $\rightarrow$ I_Basiléia. Como o trabalho não envolve a derivação formal de um modelo teórico, uma combinação da literatura foi adotada para fundamentar os pressupostos de ordenamento entre as variáveis.

O arranjo inicial com variáveis macroeconômicas consideradas como fracamente exógenas dado por - IPCA $\rightarrow$ Selic $\rightarrow$ Compulsório foi baseado em Peersman \& Smets (2001), que utilizaram um VAR com dados trimestrais para investigar mecanismos de transmissão da política monetária na área do Euro. Assim, essa identificação tem como premissa que, ao estabelecer a política monetária, o Banco Central está reagindo às expectativas de variação no nível de preços dos bens de consumo.

A opção por manutenção da variável compulsório como mais endógena do que a taxa de juros foi feita com base em Montoro \& Moreno (2011), que discutem o uso do requerimento compulsório na América Latina e destacam que isto ocorre de forma complementar e/ou substituta à taxa de juros de política. Nesse sentido, deve-se considerar, inclusive, que dentre as justificativas tratadas na literatura para o uso das reservas compulsórias, especialmente para o Brasil, está o reforço à atuação da política monetária via taxa de juros, ratificando o aspecto de complementaridade e endogeneidade entre essas políticas. 
Consideramos que os efeitos de política sobre a atividade bancária são mais contemporâneos do que o inverso, tendo em vista, além do fato de utilizarmos uma estrutura de micro dados para as variáveis bancárias, a existência de vasta literatura que discute efeitos contemporâneos de políticas monetárias e macroprudenciais sobre variáveis de desempenho bancário. Gambacorta (2009) e Agur \& Demertzis (2012) retratam efeitos incidentes sobre riscos bancários a partir de política monetária via juros, assim como Carvalho \& Castro (2015) que mencionam que o uso de requerimento compulsório também afeta a tomada de riscos pelos bancos.

Quanto as posições utilizadas no ordenamento entre as variáveis bancárias $-R$ _Crédito $\rightarrow R$ _Mercado $\rightarrow$ Liquidez $\rightarrow$ Lucro $\rightarrow I$ IBasiléia -, tem-se como ponto de partida para considerar medidas de risco como mais exógenas o argumento teórico exposto em Delis \& Karavias (2015), no sentido de gestores de bancos tomarem decisões de riscos sobre ativos e passivos de modo a produzirem lucros.

Assim, a suposição feita para períodos trimestrais é de que as exposições a diferentes riscos financeiros provocam reflexos contemporaneamente no lucro dos bancos. Embora seja aventada a possibilidade de que os lucros observados também possam influenciar nas decisões de maior ou menor assunção de riscos, espera-se que essa relação, caso existente, seja não contemporânea, envolvendo ao menos certa defasagem temporal entre a apuração do resultado e as decisões estratégicas de riscos para um período futuro próximo.

A variável ÍBasiléia foi mantida como mais endógena num horizonte trimestral, sob a suposição de que esse índice responde contemporaneamente às demais variáveis do modelo. No caso do Índice de Basiléia, a alteração do índice de capital se materializa concomitante a aumentos no patrimônio, dado inclusive pela obtenção de lucros auferidos, ou por alterações em volumes de crédito e ou condições de riscos associadas aos ativos e passivos contratados. Já para as demais variáveis bancárias, embora também sejam esperadas respostas ao nível de índice de Basiléia, assume-se que haja uma certa defasagem decorrente do tempo de apuração e decisões decorrentes.

Já o ordenamento dado exclusivamente entre as variáveis que envolvem riscos financeiros $-R_{-}$Crédito $\rightarrow R_{-}$Mercado $\rightarrow$ Liquidez foi feito considerando, inicialmente, a interação entre riscos de crédito e riscos de mercado, em decorrência do grau de integração entre essas métricas, conforme discutido em Liang et. al (2013). Além disso, supõese predominância e maior representatividade do risco de crédito em 
relação ao risco de mercado e decorrente resposta contemporânea da liquidez bancária às escolhas em portfólios com maior ou menor risco.

Por fim, menciona-se que ordenamentos adicionais ${ }^{2}$, com alternâncias entre as posições das variáveis de política (compulsório previamente à taxa de juros) e entre as variáveis bancárias, foram testados e os resultados foram preservados na quase totalidade. Tal evidência de preservação dos resultados sob procedimentos alternativos de identificação encontra respaldo em Christiano et. al (1998) que, em um VAR tradicional, sugerem haver uma indiferença no ordenamento anterior e posterior a variáveis de política, desde que sejam bem definidas quais variáveis afetam contemporaneamente as variáveis de política e quais são afetadas pelas medidas de políticas.

\subsection{Exercícios de Robustez}

Além dos tradicionais testes de diagnóstico exigidos para assegurar qualidade às estimações como avaliação da estacionaridade das séries, seleção da ordem ideal de defasagens através de critérios de informação, análise da condição de estabilidade do VAR e adoção de ordenamentos alternativos na decomposição de Choleski, especificações alternativas são avaliadas com o intuito de ilustrar a robustez dos resultados.

Nesse sentido, 4 especificações alternativas são consideradas para os modelos estimados. Além da especificação base descrita na seção 3.1, com os vetores de variáveis $W_{t}, X_{i, t}$ e $C_{t}^{1}$, tanto para a totalidade de bancos da amostra (Modelo 1), como exclusivamente para bancos com capital privado (Modelo 2), são feitos exercícios adicionais com a inclusão do vetor de controle $C_{i, t}^{2}$, relativo a variável Estabilidade. As estimações alternativas ocorrem para a totalidade dos bancos (Modelo 3) e exclusivamente para os bancos privados (Modelo 4). Dessa forma, são estimados os seguintes modelos alternativos:

Modelo 1: $W_{t}, X_{i, t}$ e $C_{t}^{1}$ com $i \in\{$ Amostra total de bancos $\}$;

Modelo 2: $W_{t}, X_{i, t}$ e $C_{t}^{1} \operatorname{com} i \in\{$ Bancos privados da amostra\};

\footnotetext{
${ }^{2}$ Os exercícios com ordenamentos alternativos entre variáveis de política e entre variáveis bancárias totalizaram 6 estimações adicionais, além da especificação padrão e exercícios de robustez discutidos na seção 3.3, resultando em um total de 10 estimações sem conflitos relevantes de resultados. Parte desses resultados foi suprimida do artigo devido a limitação de espaço, mas estão disponíveis para consulta mediante solicitação.
} 
Modelo 3: $W_{t}, X_{i, t}, C_{t}^{1}$ e $C_{i, t}^{2} \operatorname{com} i \in\{$ Amostra total de bancos $\}$;

Modelo 4: $W_{t}, X_{i, t}, C_{t}^{1}$ e $C_{i, t}^{2} \operatorname{com} i \in\{$ Bancos privados da amostra $\}$.

\section{Resultados}

\subsection{Descrição dos dados}

Foram utilizados dados trimestrais relativos a 56 instituições financeiras que atuaram no Brasil durante o período de 2001:1 a 2013:4 e indicadores de política monetária e macroprudencial para esse mesmo período, que totaliza 52 trimestres. Os dados relativos a painel contemplam todos os bancos comerciais com informações completas para o período estudado. O período inicial das observações foi definido pelo começo da disponibilização de algumas das informações por parte do Banco Central do Brasil.

As séries variantes entre indivíduos foram transformadas em logaritmo. Constam, na Tabela 1, as estatísticas descritivas dos dados antes das transformações logarítmicas. Na sequência, são descritas as variáveis e a forma de apuração, sendo a fonte primária de todas os dados o Banco Central do Brasil.

\section{Tabela 1}

Estatísticas descritivas

\begin{tabular}{cccccc}
\hline Variável & Observações & Média & Des.Padrão & Mínimo & Máximo \\
\hline IPCA & 52 & 0,016 & 0,010 & 0,001 & 0,066 \\
Selic & 52 & 0,033 & 0,011 & 0,017 & 0,058 \\
Compulsório & 52 & 0,511 & 0,051 & 0,440 & 0,680 \\
R_Crédito & 2912 & 0,055 & 0,068 & 0,000 & 1,000 \\
R_Mercado & 2912 & 0,035 & 0,082 & 0,000 & 0,785 \\
Liquidez & 2912 & $-0,190$ & 0,252 & $-0,752$ & 0,492 \\
Lucro $^{1}$ & 2912 & 214 & 1.080 & -35.557 & 8.895 \\
I_Basiléia $^{2}$ & 2912 & 0,321 & 0,590 & $-0,087$ & 9,200 \\
Estabilidade $^{2}$ & 2912 & 16,408 & 29,359 & $-2,416$ & 422,374
\end{tabular}

Notas: 1 - Valores em milhões de R\$. O mínimo na amostra para a variável lucro operacional é relativa aos efeitos da aquisição do Unibanco pelo Itaú no $4^{\circ}$ trimestre de 2008. 2 - O máximo da variável índice de Basiléia decorre da heterogeneidade das instituições que compõem o SFN, havendo pequenos bancos comerciais com baixo nível de aplicação, especialmente crédito, e perfil excessivamente capitalizado. 
$I P C A$ - Série de inflação trimestral dada pela variação percentual do Índice de Preços ao Consumidor Amplo (IPCA), mensurado e divulgado pelo Instituto Brasileiro de Geografia e Estatística (IBGE).

Selic - Taxa básica de juros (Over Selic) capitalizada trimestralmente. A Selic é a taxa média dos negócios com títulos públicos no âmbito do Sistema Especial de Liquidação e Custódia, sendo considerada referência de taxa de juros livre de risco da economia brasileira e principal instrumento utilizado pela autoridade monetária.

Compulsório - Alíquota máxima de requerimento compulsório exigido sobre os depósitos à vista captados pelos bancos. Apesar dos objetivos para imposição de requerimentos compulsórios envolver, segundo Gray (2011), controle monetário, objetivos prudenciais e gestão de liquidez, para Tovar et al. (2012), a recente utilização intensiva sobre depósitos tem sido caracterizada primordialmente como instrumento de política macroprudencial focada em objetivos contracíclicos sobre o crédito e gestão da liquidez.

$R \_C r e ́ d i t o$ - Consiste na razão entre o estoque de provisões de crédito, calculados com base na Resolução CMN 2682/99, e o total de aplicações em operações de crédito. Conforme aborda Zhang et al. (2013), trata-se de proxy para expressar o nível de exposição da instituição financeira ao risco de crédito, sendo que, quanto maior o índice mais provável que o Banco venha a sofrer eventos de default.

$R \_$Mercado - Razão entre o volume total de captações no interbancário e os passivos exigíveis totais. Zhang et al. (2013) sugerem essa métrica como proxy para risco de mercado com base no fato que quanto maior for a parcela dos passivos do banco no interbancário, maior é a vulnerabilidade da instituição às taxas de juros de mercado.

Líquidez - Índice de liquidez para instituições financeiras calculado a partir de dados contábeis, baseado em Berger \& Bouwman (2009) e Distinguin et al. (2013), conforme fórmula de apuração que segue ${ }^{3}$ :

\footnotetext{
${ }^{3}$ Com base em Distinguin et al. (2013), as contas de ativo e passivo dos bancos foram classificadas pelo grau de liquidez em: ativos líquidos (disponibilidades); ativos semilíquidos (aplicações interfinanceiras e TVM e instrumentos financeiros derivativos); ativos ilíquidos (operações de crédito e arrendamento mercantil, Imobilizado, Permanente e Outros); passivos líquidos (depósitos à vista, depósitos a prazo, outros depósitos e poupança); passivos semilíquidos (depósitos interfinanceiros, captações no mercado aberto e recursos de aceites e emissões de títulos) e passivos ilíquidos (patrimônio líquido e outros passivos).
} 
$\{(0,5$ ativos ilíquidos $)+(0$ ativos semilíquidos $)-(0,5$ ativos líquidos $)+$ $\underline{(0,5 \text { passivos líquidos })+(0 \text { passivos semilíquidos })-(0,5 \text { passivos ilíquidos })\}(-1)}$

Nesse caso, quanto maior o índice, maior a capacidade da instituição em dar sustentação em termos de caixa às atividades de intermediação financeira, de forma a suportar eventuais desequilíbrios financeiros entre captações e aplicações.

Lucro - Lucro operacional auferido pelas instituições no trimestre, corrigido monetariamente pelo índice de preços ao consumidor amplo (IPCA).

I_Basiléia - Índice calculado e divulgado pelas instituições financeiras como métrica de adequação de capital. Trata-se de um conceito definido pelo Comitê de Basiléia em termos de relação entre o patrimônio da instituição financeira e um conjunto de riscos ponderados. No Brasil a relação mínima exigida atualmente é de $11 \%$, sendo a regulamentação inicial dada pela Resolução CMN 2099/1994.

Estabilidade - Medida de estabilidade da indústria bancária, calculada por instituição, considerando a tradicional medida ZSCORE que, conforme Uhde \& Heimeshoff (2009), denota uma medida de solvência dada pelo grau de capitalização, capacidade de geração de resultados e volatilidade dos retornos

$$
\frac{\text { Rentabilidade }+K}{\text { Desvio Padrão (Rentabilidade) }}
$$

O cálculo do índice é derivado de dados contábeis, sendo adotada como medida de rentabilidade o "Retorno sobre o Patrimônio Líquido", "K" obtido pela razão entre o patrimônio e o total de ativos e o desvio padrão calculado com base em 5 períodos.

Dummy de Juros - variável binária que modela a quebra estrutural na tendência da taxa básica de juros (Over Selic). A partir do terceiro trimestre de 2013, o Banco Central interrompeu a sequência de altas na taxa de juros Over Selic. Houve uma acomodação das expectavas adversas decorrentes do período eleitoral, com a redução nas pressões inflacionárias e o início de um período marcado por sucessivas quedas naquela taxa de juros. Dessa forma, períodos anteriores a 2003:3, quando a taxa de juros apresentou uma trajetória ascendente, foram definidos como 0. O restante da amostra, a partir de 2013:3, assumiu valor 1, quando a taxa de juros iniciou uma trajetória decrescente. 


\subsection{Estimações e análises}

Previamente a estimação dos modelos, foi constatado que as séries temporais e de dados em painel seguem processos estocásticos estacionários. Os procedimentos de verificação adotados por meio dos testes propostos por Levin et al. (2002), Im et al. (2003), Elliot et al. (1996), Ng \& Perron (2001) e Perron (1989) estão detalhados e os resultados reportados nas Tabelas A1 e A2 do Apêndice A.

A seleção da ordem de defasagens para os modelos VAR em painel estimados teve como base os critérios de informação de Akaike modificado (MAIC), Bayesiano modificado (MBIC) e Hannan-Quinn (MQIC). Os resultados recomendaram a estimação do modelo com apenas 1 defasagem. ${ }^{4}$

As estabilidades dos modelos VAR em painel foram avaliadas a partir da análise das raízes dos polinômios característicos correspondentes. Conforme ilustrado na Figura B.1, no Apêndice B, observa-se que as raízes inversas se encontram dentro do círculo unitário. Isso assegura estabilidade em todas as especificações estimadas, afastando a possibilidade de trajetórias explosivas. ${ }^{5}$

A próxima seção apresenta as funções de impulso resposta (FIR) calculadas para os 4 modelos estimados. ${ }^{6}$ Destaca-se que os resultados obtidos para os diferentes modelos foram muito próximos, indicando a robustez da evidência empírica.

\subsubsection{FIR para um choque na política monetária}

A Figura 1 reporta os resultados para um choque positivo de um desvio padrão na política monetária, representada pela taxa de juros do Over Selic. Esse choque provoca imediata piora no risco de crédito dos bancos, com retorno ao patamar original dentro do mesmo ano.

\footnotetext{
${ }^{4}$ As estimativas foram feitas por meio do software Stata versão 12.1, a partir dos códigos desenvolvidos por Inessa Love do Departamento de Economia da University of Hawaii at Manoa.

${ }^{5}$ Embora as estimações no presente trabalho envolvam GMM com uso de instrumentos, a modelagem proposta é exatamente identificada, com quantidade de parâmetros estimados idêntica a quantidade de condições de ortogonalidade, não requerendo assim a inspeção por testes de sobreidentificação.

${ }^{6}$ Os intervalos de confiança nas Funções de Impulso Resposta (FIR) produzidas são definidos com base em simulações de Monte Carlo com o $5^{\circ}$ e $95^{\circ}$ percentil da distribuição após sucessivas iterações.
} 
Essa relação observada entre a taxa de juros e o risco de crédito mostrou-se estatisticamente significante até aproximadamente 2 trimestres. A sua sustentação na literatura pode ser buscada nos argumentos associados ao efeito substituição, como apontado por Agur \& Demertzis (2012), e ao problema de seleção adversa discutido por Stiglitz $\&$ Weiss (1981).

O efeito substituição envolve o fato do aumento na taxa de juros encarecer os custos de captação, incentivando os bancos a assumirem maiores riscos em operações ativas mais rentáveis como forma de compensar a perda nas margens financeiras. Já o problema de seleção adversa entre bancos e o perfil dos clientes decorre da existência de demanda de crédito por tomadores de empréstimos com maior probabilidade de default e um maior prêmio de risco exigido pelos bancos em contextos de juros mais elevados. Isso pode afetar, de forma discriminante, os potenciais tomadores de crédito, afastando os bons pagadores, dada a assimetria de informação existente.

Efeitos negativos de maiores taxas de juros sobre as expectativas dos agentes, atividade econômica e comprometimento da renda das famílias também ajudam a explicar o resultado observado entre o choque na taxa selic e o risco de crédito.

Pelo mesmo estímulo na taxa de juros, percebe-se também, embora de forma mais amena e com menor velocidade de retorno ao nível inicial, incremento no risco de mercado. Os resultados estimados são significantes estatisticamente para períodos superiores a 1 ano em todos os modelos estimados. Provavelmente estão associados a maior volatilidade provocada sobre os ativos após elevação de juros, conforme destaca, Agur \& Demertzis (2012), bem como a potenciais descasamentos de taxas em operações ativas e passivas.

Em parte dos modelos estimados, percebe-se no curto prazo que a política monetária restritiva, mediante aumento de juros, provoca efeito positivo sobre a liquidez bancária. Nesse caso, atribui-se tanto a reação bancária de preferência por liquidez, dadas expectativas de maior risco e incerteza como enfatiza Minsky (1986), quanto à redução da demanda por crédito e a atratividade no Brasil das aplicações mais líquidas em títulos públicos.

Em relação ao lucro das instituições, diferentemente das evidências obtidas por Gerali et al.(2010) para bancos Europeus, observou-se que a política monetária restritiva no Brasil vem provocando imediata queda no lucro operacional dos bancos no curto prazo. 

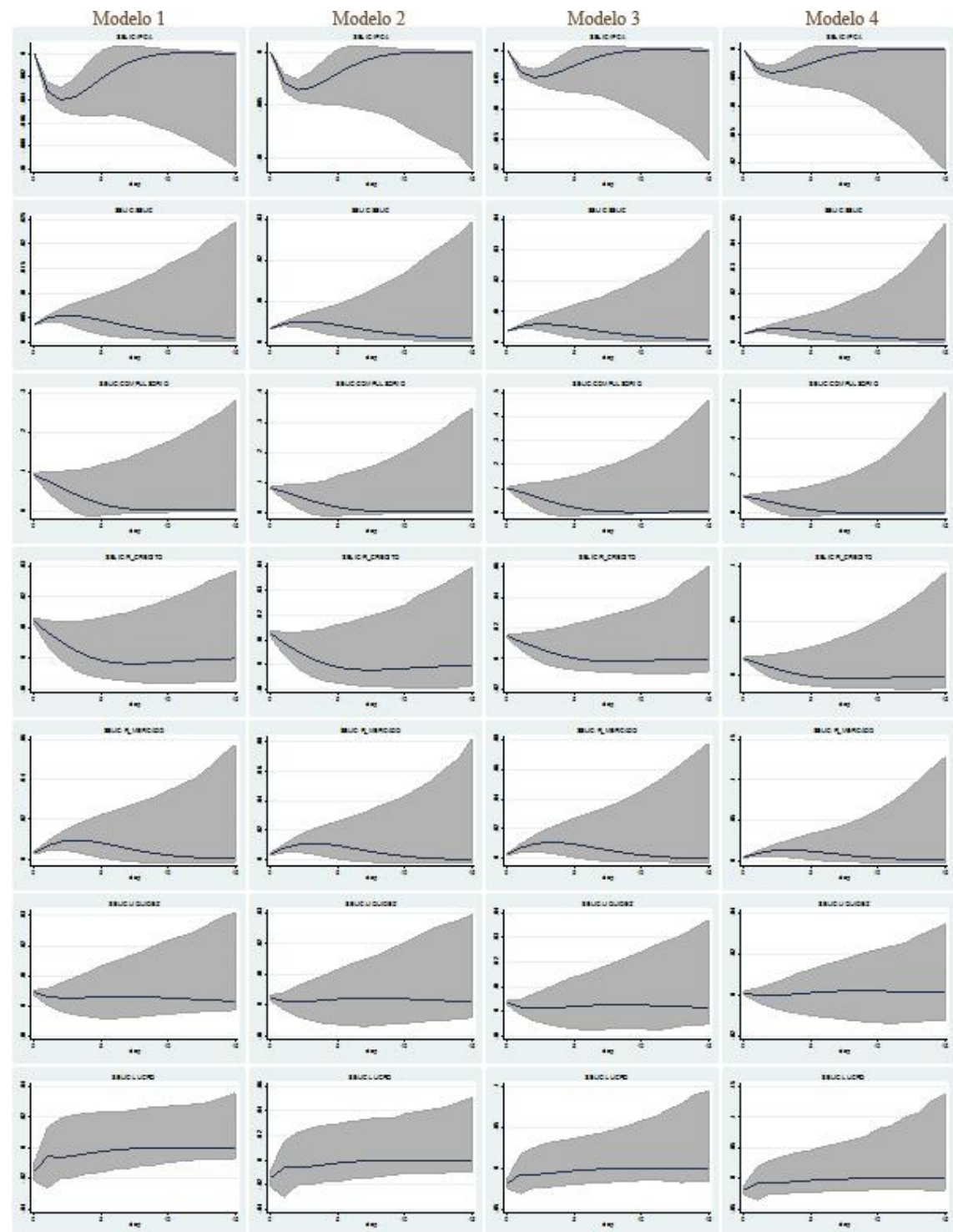

Figura 1

FIR para um choque na taxa de juros do Over Selic 


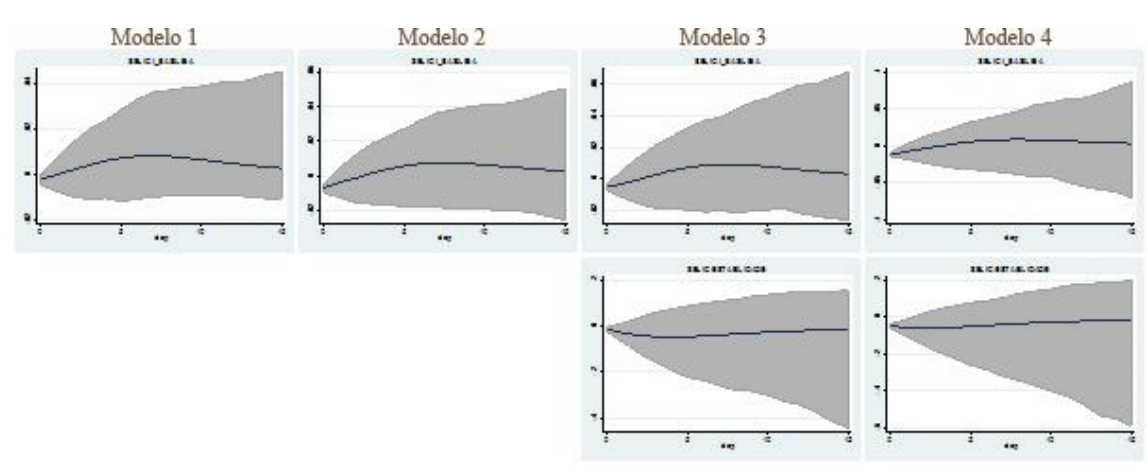

Cont. Figura 1

FIR para um choque na taxa de juros do Over Selic

Nesse sentido, os bancos que atuam no Brasil com maior ênfase em operações de crédito para pessoas físicas possuem as operações ativas predominantemente contratadas com taxas pré-fixadas, enquanto as captações com taxas pós-fixadas. Logo, elevações na taxa básica de juros, dada impossibilidade de reapreçamento imediato sobre os estoques de operações contratadas, pode, no curto prazo, vir a desfavorecer as margens financeiras e o lucro dos bancos como constatado.

A respeito do Índice de Basiléia, em parte dos modelos estimados (2, 3 e 4), também foram observados para um curto período inicial com significância estatística, que um choque na Selic ocasionou leve redução nesse índice de adequação de capital. Embora haja evidências na literatura sugerindo que o aumento nos juros reduz a oferta de crédito e, consequentemente, beneficia a formação de buffer de capital [Tabak et al. (2011) e Carvalho et al. (2013)], os efeitos encontrados dessa política monetária restritiva sobre o maior nível de exposição a riscos, bem como os efeitos de deterioração do patrimônio da firma bancária, como abordado por Van den Heuvel (2006), alimentam outras suposições para compreender o efeito dos juros sobre o Índice de Basiléia.

Apesar da rápida perda de significância estatística na FIR da Selic sobre o Índice de Basiléia, percebe-se que após a imediata redução do Índice de Basiléia tem-se a retomada do índice ao patamar original em curto espaço de tempo, inclusive com provável inversão de trajetória. Essa inversão possivelmente se daria à medida que a preferência por liquidez pelos bancos passasse a prevalecer, com troca das posições em crédito por títulos públicos, que, segundo normas de Basiléia, exigem menos capital, refletindo na maior formação de buffers como já discutido na literatura. 
$\mathrm{Na}$ mesma direção e com certa limitação em termos de poucos períodos de significância estatística e validade somente para o modelo (4), o resultado negativo que a política monetária exerce sobre a estabilidade bancária mostra-se em linha com os resultados indesejados que o aumento dos juros provoca sobre exposições a riscos, geração de lucro e adequação de capital.

\subsubsection{FIR para um choque na política macroprudencial}

No que tange a política de requerimento compulsório sobre os depósitos à vista, observa-se que, a partir de um choque de um desvio padrão nessa variável reproduzido na Figura 2, os efeitos sobre o comportamento dos riscos de crédito e de mercado, liquidez, índice de capital e estabilidade financeira são similares àqueles observados a partir do choque na política monetária. Nos dois ambientes há, igualmente, piora nos riscos, aumento da liquidez e redução dos índices de Basiléia e de estabilidade.

Em relação ao risco de crédito, tendo em vista que o compulsório provoca custos adicionais de captação (Ramos-Tallada, 2015), especialmente se considerarmos que os bancos buscam formas alternativas de captação para garantir funding para as operações ativas, o efeito substituição e de seleção adversa discutidos anteriormente como influentes sobre a maior exposição quando se eleva os juros, também ocorrem no caso do aumento do requerimento compulsório, justificando as evidências ora encontradas.

Oliveira \& Andrade Neto (2008) ratificam esse aspecto envolvendo o compulsório com mudanças na estrutura de funding dos bancos ao descreverem a existência de indícios de que as instituições financeiras procuram alternativas aos depósitos à vista, após choques de recolhimento compulsório sobre essas captações. Sugerem, ainda, que os bancos conseguem substitui-los de forma eficaz mediante outras fontes de captação (poupança e depósito a prazo) ou através da emissão de outros instrumentos e obrigações.

Dessa forma, o efeito do requerimento compulsório sobre a estrutura passiva dos bancos desponta como principal indício de fator responsável pelo incremento e elevado tempo de dissipação (superior a 1 ano) do comportamento observado para o risco de mercado após o choque no compulsório. 

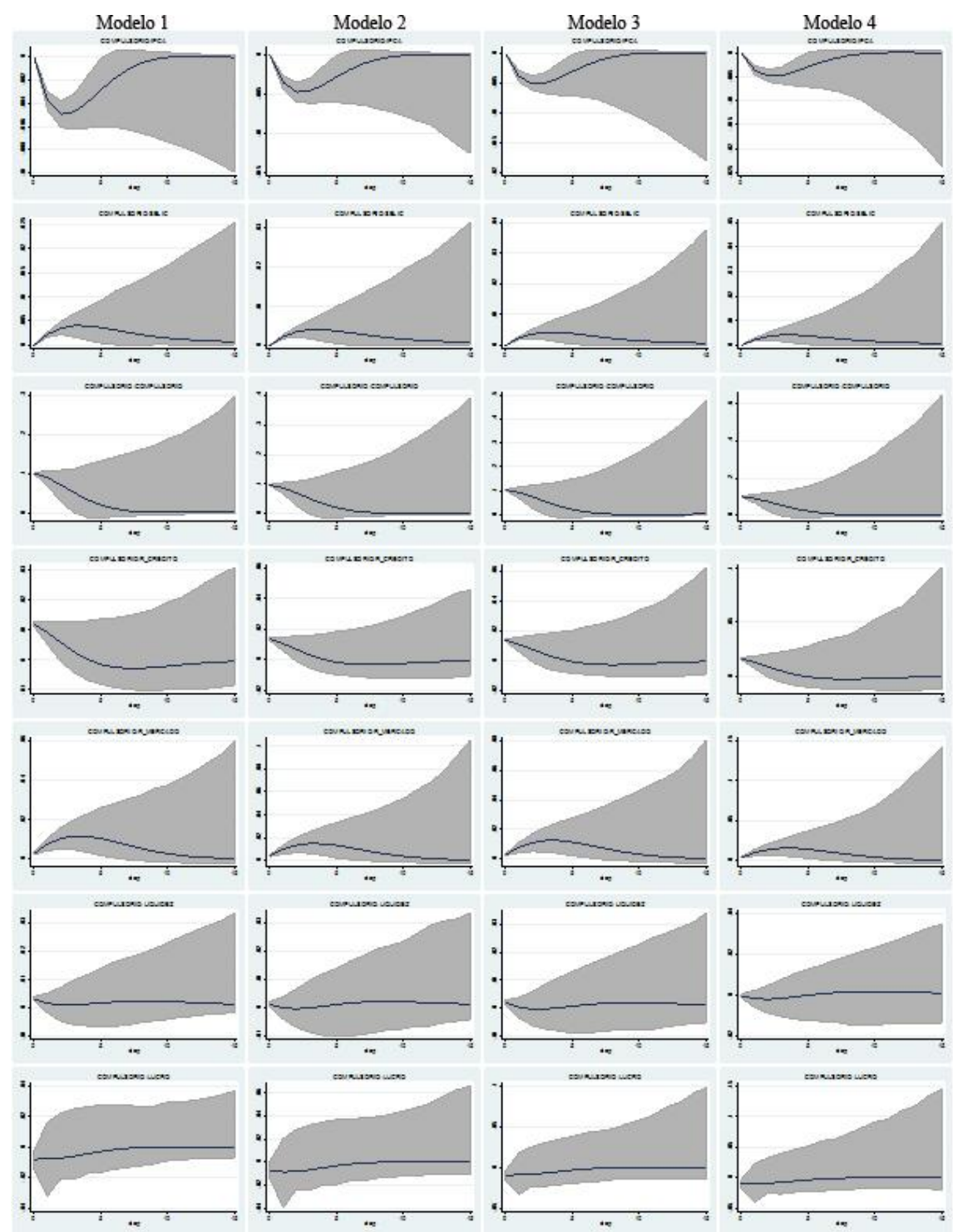

Figura 2

FIR para um choque na taxa de requerimento compulsório 


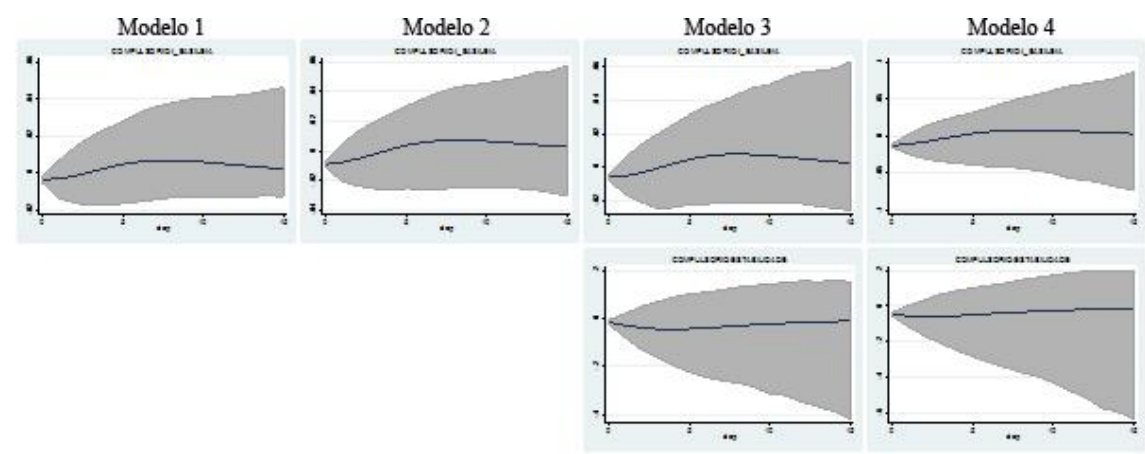

Cont. Figura 2

FIR para um choque na taxa de requerimento compulsório

Embora observe-se nos modelos (1) e (3) que o efeito do compulsório sobre a liquidez é semelhante ao do aumento nos juros, o suposto motivo, no caso do compulsório, de acordo com Gray (2011), está relacionado com o fato dos requerimentos de reservas garantirem que os bancos preservem certa proporção de ativos líquidos de alta qualidade. São ativos de reserva equivalentes a uma fração de seus passíveis exigíveis de curto prazo, garantindo a cobertura parcial em caso de demanda de recursos pelos depositantes.

Quanto aos efeitos capturados do compulsório sobre o Índice de Basiléia e na estabilidade bancária, os resultados com significância estatística exclusivamente no curtíssimo prazo e somente em parte dos modelos estimados, também se mostram alinhados com os efeitos provocados por aumentos na taxa básica de juros, no sentido de deterioração do nível de capital e da solvência bancária.

Dadas evidências encontradas, sugerindo que tanto a política monetária via aumentos na taxa de juros, quanto a política macroprudencial via maiores requerimentos compulsórios sobre depósitos, em geral, provocam efeitos indesejados sobre o nível de riscos e capital dos bancos, bem como sobre a estabilidade bancária. Isso ressalta o trade-off encontrado pelo Banco Central no Brasil que consolida funções de autoridade monetária e de supervisão e regulação do sistema bancário brasileiro.

No mesmo sentido, também podemos ressaltar que tais resultados se inserem na questão envolvendo regimes de metas de inflação, em termos de compromissos e instrumentos utilizados produzirem potencial geração de perda para a estabilidade financeira, assim como discutido por Fouejieu (2013) e Frappa \& Mesonnier (2010). 
Outro resultado interessante que também pode ser observado diz respeito a resposta do requerimento compulsório a um choque na taxa de juros e vice-versa. As trajetórias nas direções dos choques, conforme Figuras 1 e 2, demonstram existir complementaridade entre ambas as políticas que, aparentemente, vem sendo utilizadas de forma conjunta. Tais resultados mostram-se alinhados com as evidências e posição de Montoro \& Moreno (2011), Tovar et al. (2012), Cecchetti \& Kohler (2012) e Agénor \& Silva (2013).

Com isso, aventa-se também que essa interação discutida entre a Selic e o requerimento compulsório possa existir quando se torna difícil e ou desgastante para a autoridade monetária não independente a possibilidade de novos aumentos na Selic, dados custos políticos associados a sucessivas elevações na taxa básica de juros.

Ademais, não foram encontradas relações adicionais que permitam inferir com segurança que as variáveis de desempenho bancário possam estar orientando a formação das políticas em questão.

Quanto aos efeitos envolvendo a taxa de juros, o requerimento compulsório e a inflação, os resultados reportados na Figura B.2, no Apêndice $\mathrm{B}$, indicando respostas positivas dos juros e compulsório ao choque inflacionário, revelam que ambos os instrumentos vêm sendo utilizados em resposta a pressões inflacionárias, em concordância com a literatura relevante.

Na mesma direção, a resposta da inflação a choques na taxa de juros e compulsório, conforme capturado nas Figuras 1 e 2, alimentam a crença quanto a efetividade desses instrumentos no controle monetário, destacando, entretanto, quedas mais acentuadas da inflação em resposta ao compulsório, comparativamente a taxa de juros.

\subsubsection{FIR para choques exógenos nas variáveis bancárias}

Além dos efeitos das políticas monetária e macroprudencial sobre a atividade bancária como discutido nas seções anteriores, relações cruzadas entre as próprias medidas de riscos e desempenho dos bancos também se observam, conforme reportado nas seções de Apêndice ${ }^{7} 3,4$, $5,6,7$ e 8 .

\footnotetext{
${ }^{7}$ Os resultados das FIR que não apresentaram significância estatística foram supridos do artigo para economizar espaço, mas estão disponíveis mediante solicitação.
} 
Em relação ao risco de crédito, que é o principal fator de risco a que estão expostos os bancos, pôde-se constatar na Figura B.3, no Apêndice $\mathrm{B}$, que choques nessa variável são acompanhados por majorações também no risco de mercado e imediata piora na estabilidade financeira.

Esses resultados servem de alerta quanto aos possíveis efeitos conjuntos dos fatores de riscos financeiros nas instituições bancárias, além da ameaça à solidez do sistema financeiro em contextos de maior inadimplência.

No caso do efeito sobre o risco de mercado, em que se verifica resposta ao choque no risco de crédito com lenta dissipação ao longo dos trimestres, merece atenção o fato de tal resultado ir ao encontro da necessidade de identificação e reconhecimento de inter-relacionamentos existentes entre os tipos de riscos, ressaltada por supervisores bancários após a crise financeira global. Nesse sentido, tal resultado mostra-se alinhado também com o estudo de Liang et. al (2013) que apontam para a existência de integração entre os riscos de crédito e mercado dados fatores comuns existentes.

Com significância estatística compreendendo um período aproximado de 2 trimestres, o resultado do choque no risco de crédito sobre a liquidez, revela uma reação bancária de crescimento na liquidez. Tal resultado potencialmente decorre da postura de maior preferência por liquidez que os bancos adotam em situações de maior risco e incerteza, conforme preconiza a teoria de preferência por liquidez e evidências obtidas por Munteanu (2012).

Em relação aos efeitos de choques no risco de mercado, apresentados na Figura B.4, no Apêndice B, como era de se esperar, percebe-se efeito negativo imediato sobre o índice de adequação do capital. Entretanto, a FIR do risco de mercado sobre a estabilidade, de forma contra intuitiva, indicou que a estabilidade financeira responde de forma positiva à maior exposição ao risco de mercado, embora tal trajetória seja estatisticamente significante para apenas um período aproximado de 1 trimestre e com tendência de rápida retomada do índice ao patamar original.

Quanto ao índice de liquidez, na Figura B.5, no Apêndice B, além das FIR capturar correspondências com aumentos da taxa Selic e do requerimento compulsório, constata-se efeitos positivos, imediatos e momentâneos que choques na liquidez podem provocar sobre o Índice de Basiléia. 
Dada ausência de significância estatística na quase totalidade das variáveis bancárias após choque no lucro dos bancos, merece destaque exclusivamente o comportamento do próprio lucro após o choque, vide Figura B.6, no Apêndice B, indicando baixa persistência dos resultados.

Tais resultados em termos de transitoriedade de lucros oferecem indícios a favor da existência de competitividade no mercado bancário brasileiro, pois, de acordo com Berger et al. (2000) e Athanasoglou et al. (2008), quando os lucros dos bancos tendem a persistirem ao longo do tempo é reflexo de impedimentos a concorrência no mercado e opacidade informativa.

No tocante à transmissão de choques no índice de Basiléia apresentados na Figura B.7, no Apêndice B, em que pese também não terem sido observadas respostas estatisticamente significante para considerável parcela das variáveis estudas, merece destaque o efeito das mudanças da adequação do capital sobre o indicador de estabilidade financeira.

Nesse caso o resultado obtido após um choque de 1 desvio padrão sobre o Índice de Basiléia descreve uma trajetória crescente para a estabilidade financeira dos bancos por um período aproximado de 1 ano, quando então o efeito tende a se dissipar, retomando ao patamar original em prazo superior a 2 anos depois do choque.

Por meio de tal resultado, permite-se reflexões favoráveis à efetividade do índice de Basiléia como instrumento de regulação em termos de fortalecimento, solvência e segurança para o sistema financeiro.

Por fim menciona-se que, exceto em relação aos choques entre as próprias variáveis, não foram encontradas entre as medidas bancárias outras relações que mereçam destaque, inclusive no que diz respeito ao indicador de estabilidade financeira contido nos modelos 3 e 4 .

\section{Considerações finais}

O objetivo desse artigo foi investigar a dinâmica da transmissão de choques exógenos nas políticas monetárias e macroprudenciais sobre segmento bancário do sistema financeiro da economia brasileira. Exploraram-se, também, os efeitos de perturbações emanadas no próprio setor bancário da economia. A investigação foi conduzida por meio da estimação de um Vetor Autorregressivo para dados organizados em 
painel, considerando 56 instituições que atuaram no mercado bancário brasileiro entre 2001 e 2013. A estrutura em cross-section do segmento bancário contribuiu para revelar inter-relações entre aspectos sistêmicos das políticas monetária e macroprudencial e o comportamento individual dos bancos.

Dentre os resultados obtidos, pode-se ressaltar o reflexo negativo de aumentos nas taxas de juros e na alíquota de requerimento compulsório sobre os níveis de exposição das instituições a riscos de crédito e de mercado, além dos impactos em termos de maior liquidez e menores níveis de capital e estabilidade financeira.

Dessa forma, medidas restritivas de políticas monetária e macroprudencial afetam negativamente a dinâmica bancária, gerando reflexões sobre a relevância daquelas medidas de políticas sobre a gestão e modelagem dos riscos e do capital dos bancos. Emerge, então, o tradeoff que o Banco Central enfrenta, especialmente em um regime de metas de inflação, à medida em que consolida as funções de autoridade monetária e de supervisão bancária na mesma instituição.

As relações encontradas entre as políticas monetária e macroprudencial revelam, em conformidade com a literatura, a existência de certa complementaridade entre os instrumentos daquelas políticas, representados pela taxa de juros e pelo requerimento compulsório, respectivamente. Ambos instrumentos responderam a pressões inflacionárias, sugerindo que o recolhimento compulsório esteja também sendo utilizado no controle da estabilidade de preços na economia. Destaca-se, ainda, o efeito mais acentuado de um choque no compulsório sobre a inflação em comparação ao efeito do choque na taxa de juros.

Considerando as interações entre as medidas de desempenho bancário, em especial àquelas decorrentes de choques no risco de crédito, que é uma relevante fonte de risco financeiro para bancos, observou-se como o nível de exposição se manifesta acompanhado por incrementos no risco de mercado e na persistente piora da estabilidade financeira. Esses resultados ressaltam a potencial integração entre os riscos de crédito e mercado, além da ameaça à solidez do sistema financeiro em contextos de maior inadimplência. Ainda em relação ao risco de crédito, os achados revelaram que os bancos buscam maior preferência por liquidez como forma de reação ao maior nível de risco.

O comportamento pouco persistente observado para o lucro operacional indicou transitoriedade dos efeitos de choques, caracterizados por rápida velocidade de ajuste ao patamar original, o que oferece 
indícios a favor da existência de competitividade no mercado bancário brasileiro.

A magnitude de reação da estabilidade financeira ao choque no Índice de Basiléia revelou a relevância e potencial efetividade da regulação bancária por meio de exigências de formação e manutenção de níveis mínimos de capital pelos bancos como forma de mitigar riscos sistêmicos e assegurar maior solvência ao sistema financeiro.

Por fim, reconhece-se a limitação na construção de algumas proxys aqui utilizadas, especialmente no que concerne aos diferentes tipos de riscos financeiros. Para pesquisas futuras, sugere-se considerar novas métricas envolvendo, por exemplo, o risco de mercado abarcando exposições cambiais. Da mesma forma, acredita-se que a inclusão de uma proxy para a dimensão Management (M) da metodologia CAMELS também possa ampliar a extensão dos resultados e suas contribuições à literatura.

\section{Referências}

Agénor, Pierre-Richard \& Silva, Luiz.A.P. 2013. Inflation targeting and financial stability: A perspective from the developing world. InterAmerican Development: Felipe Herrera Library, 120 p.

Agur, Itai \& Demertzis, Maria. 2012. Excessive bank risk taking and monetary policy. BCE Working Paper, 1457.

Altunbas, Yener, Gambacorta, Leonardo \& Marques-Ibanez, David. 2010. Bank risk and monetary policy. Journal of Financial Stability, 6, 121-129.

Arellano, Manuel \& Bover, Olympia. 1995. Another look at the instrumental variable estimation of error-components models. Journal of Econometrics, 68, 29-51.

Athanasoglou, Panayiotis P, Brissimis, Sophocles N \& Delis, Manthos. D. 2008. Bank-specific, industry-specific and macroeconomic determinants of bank profitability. Journal of International Financial Markets, Institutions \& Money, 18, 121-136.

BASEL COMITTEE ON BANKING SUPERVISION. 2010a. International regulatory framework for banks (Basel III). Bank for International Settlements, Disponível em: <http://www.bis.org/bcbs/basel3.htm>. Acesso em: 10 nov. 2014. 
BASEL COMITTEE ON BANKING SUPERVISION. 2010b. An assessment of the long-term economic impact of stronger capital and liquidity requirements. Bank for International Settlements, Disponível em: <http://www.bis.org/publ/bcbs173.htm>. Acesso em: 10 nov. 2014.

Basto, Rita B. 2013. Uma política macroprudencial para a estabilidade financeira. Relatório de Estabilidade Financeira - Banco de Portugal, 77-92.

Berger, Allen N, Bonime, Seth D \& Covitz, Daniel M. 2000. Why are bank profits so persistent? The roles of product market competition, informational opacity and regional / macroeconomic shocks. Journal of Banking \& Finance, 24, 1203-1235.

Berger, Allen N \& Bouwman, Christa H. S. 2009. Bank liquidity creation. The Review of Financial Studies, 22, 3779-3937.

Carvalho, Fábia A, Castro, Marcos R \& Costa, Sílvio M.A. 2013. Tradicional and matter-of-fact financial frictions in a DSGE model for Brazil: the role of macroprudential instruments and monetary policy. Working Paper BCB, 336.

Carvalho, Fábia A \& Castro, Marcos R. 2015. Macroprudential and monetary policy interaction: a Brazilian perspective. Working Paper $B C B, 405$.

Cecchetti, Stephen G \& Kohler, Marion. 2012. When capital adequacy and interest rate policy are substitutes (and when they are not). BIS Working Paper. 379.

Chmielewski, Tomasz. 2005. Bank Risks, Risk Preferences and Lending. MPRA Paper.5131, University Lybrary of Munich.

Christiano, Lawrence J, Eichenbaum, Martin \& Evans, Charles, L. 1998. Monetary policy shocks: what have we learned and to what end? NBER Working Paper Series, 6400.

Delis, Manthos D. \& Karavias, Yannis. 2015. Optimal versus realized bank credit risk and monetary policy. Journal of Financial Stability, 16, 13-30.

Distinguin, Isabelle, Roulet, Caroline \& Tarazi, Amine. 2013. Bank regulatory capital and liquidity: evidence from US and European publicly traded banks. Journal of Banking \& Finance, 37, 32953317. 
Elliot, Grahwa, Rothenberg, Thomas J \& Stock, James H. 1996. Efficient tests for an autoregressive unit root. Econometrica, 64, 813-836.

Fouejieu, Armand A. 2013. Inflation targeters do not care (enough) about financial stability: a myth? Investigation on a sample of emerging market economies. Université d'Orléans Working Paper, 159.

Frappa, Sébastien \& Mésonnier, Jean-Stéphane. 2010. The housing price boom of the late 1990s: Did inflation targeting matter? Journal of Financial Stability, 6, 243-254.

Galati, Gabriele \& Moessner, Richhild. 2011. Macroprudencial policy: a literature review. BIS Working Paper, 337.

Gambacorta, Leonardo. 2009. Monetary policy and the risk-taking channel. BIS Quarterly Review, 43-53.

Gerali, Andrea, Neri, Stefano, Sessa, Luca \& Signoretti, Frederico M. 2010. Credit and banking in a DSGE model of the Euro Area. Journal of Money, Credit and Banking, 42, 107-147.

Gray, Simon. 2011. Central Bank balances and reserve requirements. IMF Working Paper, 1136.

Hirtle, Beverly J \& Lopez, José. 1999. Supervisory information and the frequency of bank examinations. FRBNY Economic Policy Review, 5, 1-19.

Holtz-Eakin, Douglas, Newey, Whitney \& Rosen, Harvey S. 1988. Estimating vector autoregressions with panel data. Econometrica, 56, 1371-1395.

Im, Kyung S, Pesaran, Hashem M \& Shin, Yongcheol. 2003. Testing for unit root in heterogeneous panels. Journal of Econometrics, 115, 53-74.

Kerstein, Joseph \& Kozberg, Anthony. 2013. Using accounting proxies of proprietary FDIC ratings to predict bank failures and enforcement actions during the recent financial crisis. Journal of Accounting, Auditing \& Finance, 28, 128-151.

Kornelius, Alexandre \& Divino, José A. 2011. Monetary policy e requerimento de reserve em um modelo DSGE com fricções financeiras. XXXIII Encontro Brasileiro de Econometria da SBE, Foz do Iguaçu. Anais do XXXIII Encontro Brasileiro de Econometria. 01-42. 
Kregel, Jan. 2010. Is reregulation of the financial system an oxymoron. Levy Economics Institute of Bard College Working Paper, 585.

Lambert, Frederic \& Ueda, Kenichi. 2014. The effects of unconventional monetary policies on bank soundness. IMF Working Paper, 152.

Levin, Andrew, Lin, Chien-Fu \& Shu, Chia-Shang J. 2002. Unit Root Tests in Panel Data: Asymptotic and Finite-Sample Properties. Journal of Econometrics, 108, 1-24.

Liang, Changzhi, Zhu, Xiaoqian, Li, Yilin, Chen, Jianming \& Li, Jianming. 2013. Integrating credit and market risk: a factor copula based method. Information Technology and Quantitative Management, 17, 656-663.

Love, Inessa \& Zicchino, Lea. 2006. Financial development and dynamic investment behavior: evidence from panel VAR. The Quarterly Review of Economics and Finance, 46, 190-210.

Mazzucco, Bruno L \& Meurer, Roberto. 2013. Mudanças nos compulsórios e as ações dos bancos brasileiros. Revista Brasileira de Finanças, 11, 399-420.

Minsky, Hyman. P. 1986. Stabilizing an unstable economy. New Haven: Yale University Press, 367 p.

Mishkin, Frederic S. 1996. The channels of monetary transmission: lessons for monetary policy. NBER Working Paper Series, 5464.

Montoro, Carlos \& Moreno, Ramon. 2011. The use of reserve requirements as a policy instrument in Latin America. BIS Quarterly Review, 53-65.

Munteanu, Ionica. 2012. Bank liquidity and its determinants in Romania. Procedia Economics and Finance, 3, 993-998.

Ng, Serena \& Perron, Pierre. 2001. Lag length selection and the construction of unit root tests with good size and power. Econometrica, 69, 1519-1554.

Oliveira, Fernando N \& Andrade Neto, Renato M. 2008. A relevância do canal de empréstimos bancários no Brasil. Revista Brasileira de Finanças, 11, 357-409.

Pariès, Matthieu D, Sorensen, Christoffer K, Rodriguez-Palenzuela, Diego. 2011. Macroeconomic propagation under different regulatory 
regimes: evidence from an estimated DSGE model for the Euro area. International Journal of Central Banking, 7, 49-113

Perron, Pierre. 1989. The great crash, the oil price shock and the unit root hypothesis. Econometrica, 57, 1361-1401.

Peersman, Gert \& Smets, Frank. 2001. The monetary transmission mechanism in the euro area: more evidence from VAR. $B C E$ Working Paper. 91.

Ramos-Tallada, Julio. 2015. Bank risks, monetary shocks and the credit channel in Brazil: Identification and evidence from panel data. Journal of International Money and Finance, In press.

Stiglitz, Joseph \& Weiss, Andrew. 1981. Credit rationing in markets with imperfect information. The American Economic Review, 71, 393410.

Tabak, Benjamin M, Noronha, Ana C \& Cajueiro, Daniel. 2011. Bank capital buffers, lending growth and economic cycle: empirical evidence for Brazil. Anais do $2^{\circ}$ BIS Consultative Council for the Americas conference on "Monetary policy, financial stability and the business cycle". Ottawa.

Taylor, John B. 1995. The monetary transmission mechanism: an empirical framework. Journal of Economic Perspectives, 9, 11-26.

Tovar, Camilo. E, Garcia-Escribano, Mercedes \& Martin, Mercedes. V. 2012. Credit growth and the effectiveness of reserve requirements and other macroprudential instruments in Latin America. IMF Working Paper. 142.

Tymoigne, Éric. 2010. Financial stability, regulatory buffers, and economic growth: some postrecession regulatory implications. Levy Economics Institute of Bard College Working Paper, 637.

Uhde, André \& Heimeshoff, Ulrich. 2009. Consolidation in banking and financial stability in Europe: empirical evidence. Journal of Banking \& Finance, 33, 1299-1311.

Van den Heuvel, Skander. 2006. The bank capital channel of monetary policy. Society for Economic Dynamics - Meeting Paper, 512.

Zhang, Jianhua, Jiang, Chunxia, Qu, Baozhi \& Wang, Peng. 2013. Market concentration risk-taking and bank performance: evidence from emerging economies. International Review of Financial Analysis, 30, 140-157. 
Política Monetária, Macroprudencial e Bancos: Evidências Empíricas usando VAR em Painel

@() Revista Brasileira de Finanças (Online), Rio de Janeiro, Vol. 13, N. 4, October 2015725 


\section{Apêndice A}

\section{Testes de raiz unitária}

Para as variáveis de painel, foram aplicados os testes propostos por Levin et al. (2002) e Im et al. (2003), tradicionalmente conhecidos por LLC e IPS, respectivamente. A seleção de defasagens para esses testes levou em conta o critério de informação de Akaike.

Os resultados apresentados na Tabela A1 indicam que, em todos os testes e construções realizadas, a hipótese nula de existência de raiz unitária foi rejeitada a 5\% de significância, indicando assim que as séries de painel em estudo são estacionárias.

Tabela A.1

Estacionaridade das séries de painel

\begin{tabular}{|c|c|c|c|c|c|c|c|c|}
\hline \multirow{3}{*}{ Variável } & \multicolumn{4}{|c|}{ LLC } & \multicolumn{4}{|c|}{ IPS } \\
\hline & \multicolumn{2}{|c|}{$\begin{array}{c}\text { Tendência e } \\
\text { Intercepto }\end{array}$} & \multicolumn{2}{|c|}{ Intercepto } & \multicolumn{2}{|c|}{$\begin{array}{c}\text { Tendência e } \\
\text { Intercepto }\end{array}$} & \multicolumn{2}{|c|}{ Intercepto } \\
\hline & Adj-t & $\mathrm{Lag}^{1}$ & Adj-t & $\mathrm{Lag}^{1}$ & W-t-bar & $\mathrm{Lag}^{1}$ & W-t-bar & $\mathrm{Lag}^{1}$ \\
\hline R_Crédito & $-10,15^{* * *}$ & 0,48 & $-8,20^{* * * *}$ & 0,43 & $-9,97^{* * *}$ & 0,48 & $-9,41^{* * *}$ & 0,43 \\
\hline R_Mercado ${ }^{2}$ & $-6,87^{* * *}$ & 0,38 & $-4,02^{* * * *}$ & 0,41 & - & - & - & - \\
\hline Liquidez & $-6,82^{* * *}$ & 0,30 & $-5,48^{* * *}$ & 0,36 & $-6,16^{* * *}$ & 0,30 & $-6,40^{* * *}$ & 0,36 \\
\hline Lucro & $-28,11^{* * *}$ & 0,32 & $-22,90^{* * *}$ & 0,41 & $-27,55^{* * *}$ & 0,32 & $-25,57^{* * *}$ & 0,41 \\
\hline I_Basiléia & $-10,70^{* * * *}$ & 0,23 & $-9,21^{* * * *}$ & 0,23 & $-12,37^{* * * *}$ & 0,23 & $-12,36^{* * *}$ & 0,23 \\
\hline Estabilidade & $-9,87^{* * *}$ & 0,27 & $-7,80^{* * * *}$ & 0,30 & $-9,32^{* * *}$ & 0,27 & $-9,01^{* * *}$ & 0,30 \\
\hline
\end{tabular}

Para as séries variantes exclusivamente no tempo foram aplicados os testes modificados de Dickey-Fuller (MADF ${ }^{\mathrm{GLS}}$ ) e de Phillips-Perron $\left(\mathrm{MPP}^{\mathrm{GLS}}\right)$, propostos respectivamente por Elliot et al. (1996) e $\mathrm{Ng} \&$ Perron (2001). Para as séries apontadas inicialmente como não estacionárias, foi testada a estacionaridade na presença de quebra estrutural seguindo o teste proposto por Perron (1989). A seleção de defasagens utilizada nos testes teve como base o critério de seleção de Akaike modificado (MAIC), conforme sugerido por Ng \& Perron (2001). 
Os resultados dos testes, reportados na Tabela A2, indicam que, a níveis usuais de significância estatística, as variáveis IPCA e Compulsório são estacionárias pelos testes $\mathrm{MADF}^{\mathrm{GLS}}$ e $\mathrm{MPP}^{\mathrm{GLS}}$. Em relação à Selic, foi constatada estacionaridade com quebra estrutural de tendência no terceiro trimestre de 2003.

Tabela A.2

Estacionaridade das séries temporais

\begin{tabular}{|c|c|c|c|c|c|c|c|c|c|c|}
\hline \multirow{3}{*}{ Variável } & \multicolumn{4}{|c|}{$\mathrm{MADF}^{\mathrm{GLS}}$} & \multicolumn{4}{|c|}{$\mathrm{MPP}^{\mathrm{GLS}}$} & \multicolumn{2}{|c|}{ Perron $(1989)^{1}$} \\
\hline & \multicolumn{2}{|c|}{$\begin{array}{c}\text { Tendência e } \\
\text { Intercepto }\end{array}$} & \multicolumn{2}{|c|}{ Intercepto } & \multicolumn{2}{|c|}{$\begin{array}{l}\text { Tendência e } \\
\text { Intercepto }\end{array}$} & \multicolumn{2}{|c|}{ Intercepto } & \multicolumn{2}{|c|}{$\begin{array}{l}\text { Mudança de } \\
\text { Tendência }\end{array}$} \\
\hline & t-Stat. & Lag & t-Stat. & Lag & $\mathrm{MZt}$ & Lag & $\mathrm{MZt}$ & Lag & t-Stat. & $\mathrm{Lag}$ \\
\hline IPCA & $-1,83$ & 6 & $-1,61^{*}$ & 6 & $-1,92$ & 6 & $-1,70^{*}$ & 6 & - & \\
\hline Selic & $-2,15$ & 3 & $-0,89$ & 3 & $-2,31$ & 3 & $-0,99$ & 3 & $8,26^{* * * *}$ & 1 \\
\hline Compulsório & $-2,48$ & 0 & $-2,18^{* *}$ & 0 & $-2,14$ & 0 & $-1,98^{* *}$ & 0 & - & \\
\hline
\end{tabular}

Notas: $* * *, * * \mathrm{e} *$ denotam significância estatística a $1 \%, 5 \%$ e $10 \%$, respectivamente. 1 - O período de quebra de nível para a Selic foi 2003:3. A identificação da quebra deu-se por meio da inspeção gráfica da série. 


\section{Apêndice B}
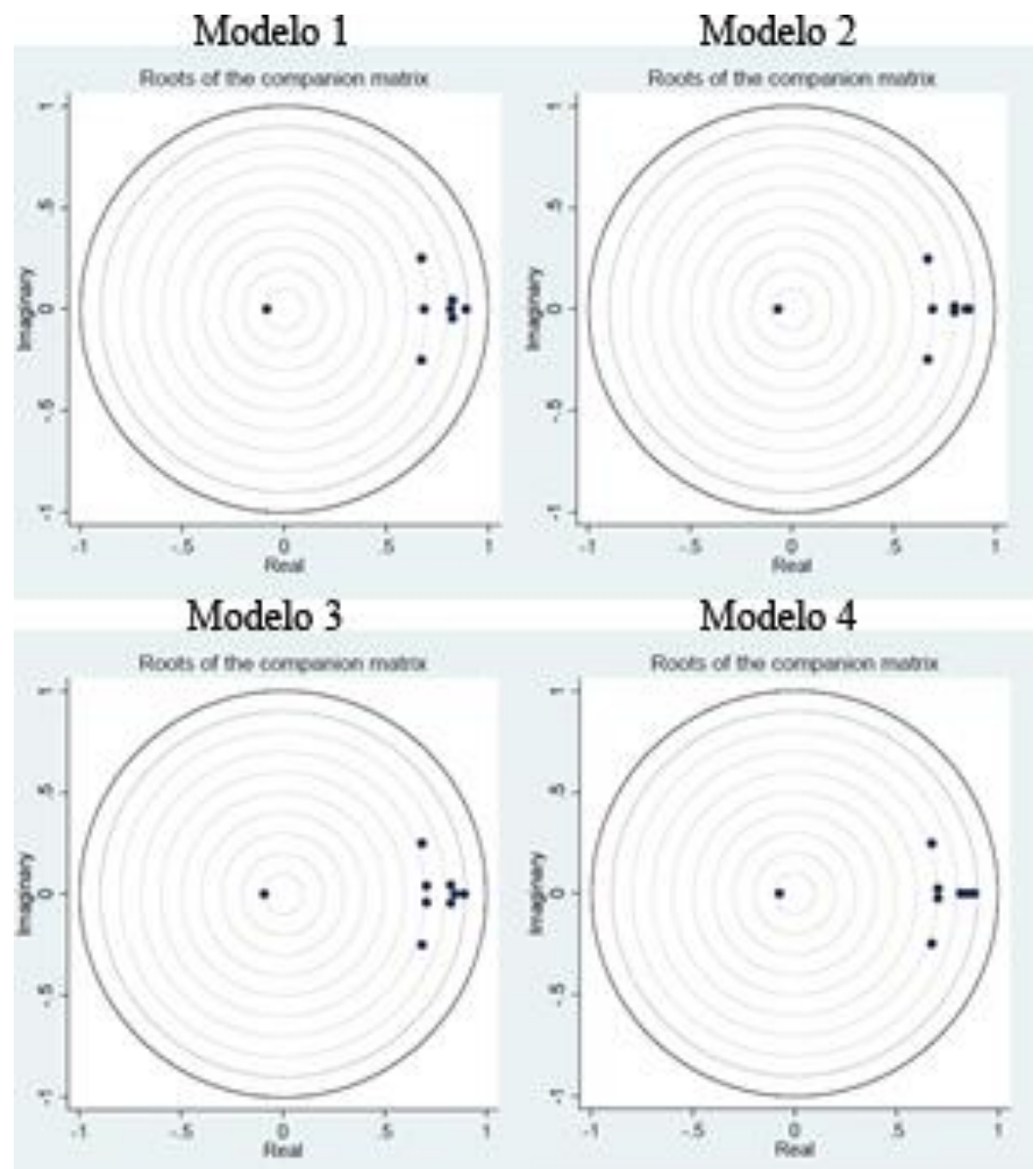

Figura B.1

Condições de Estabilidade para o VAR em painel 

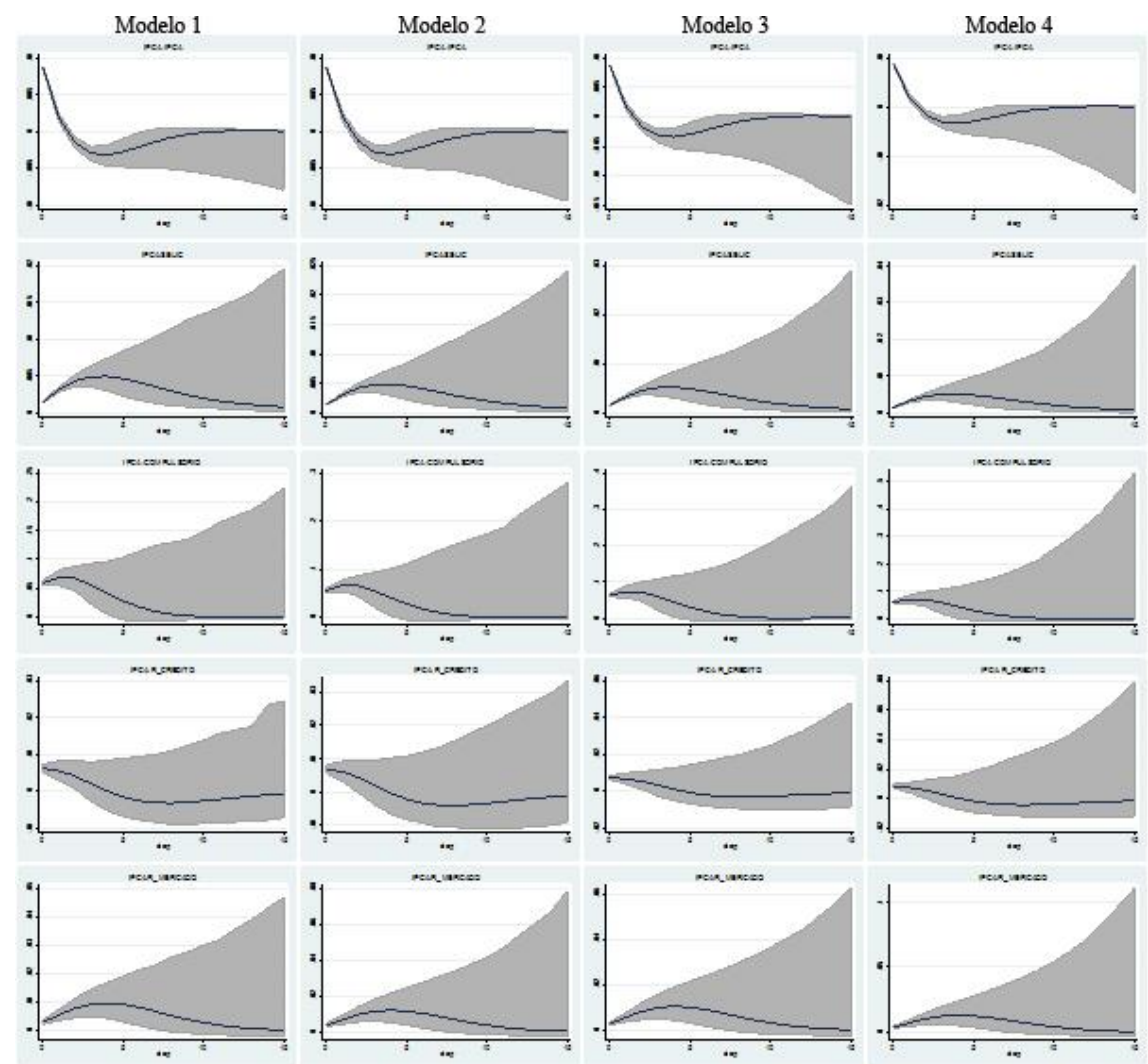

Figura B.2

FIR para um choque na taxa de Inflação 

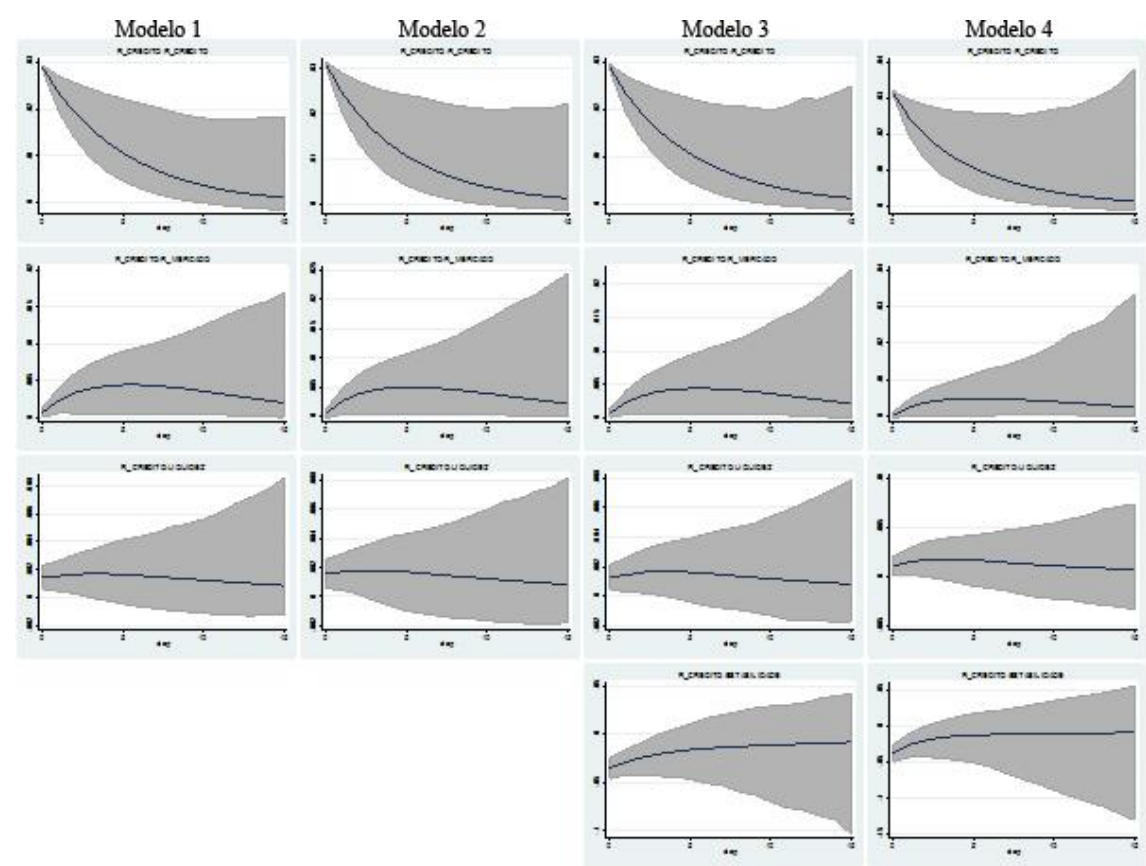

Figura B.3

FIR para um choque no risco de crédito
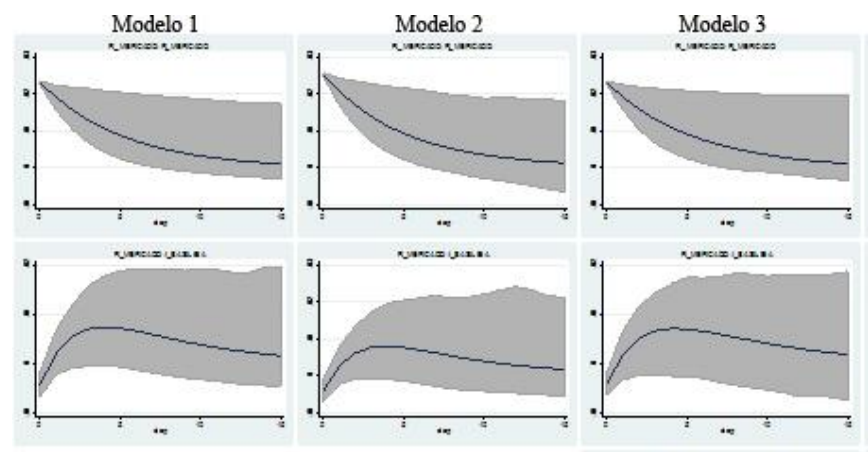

Modelo 4
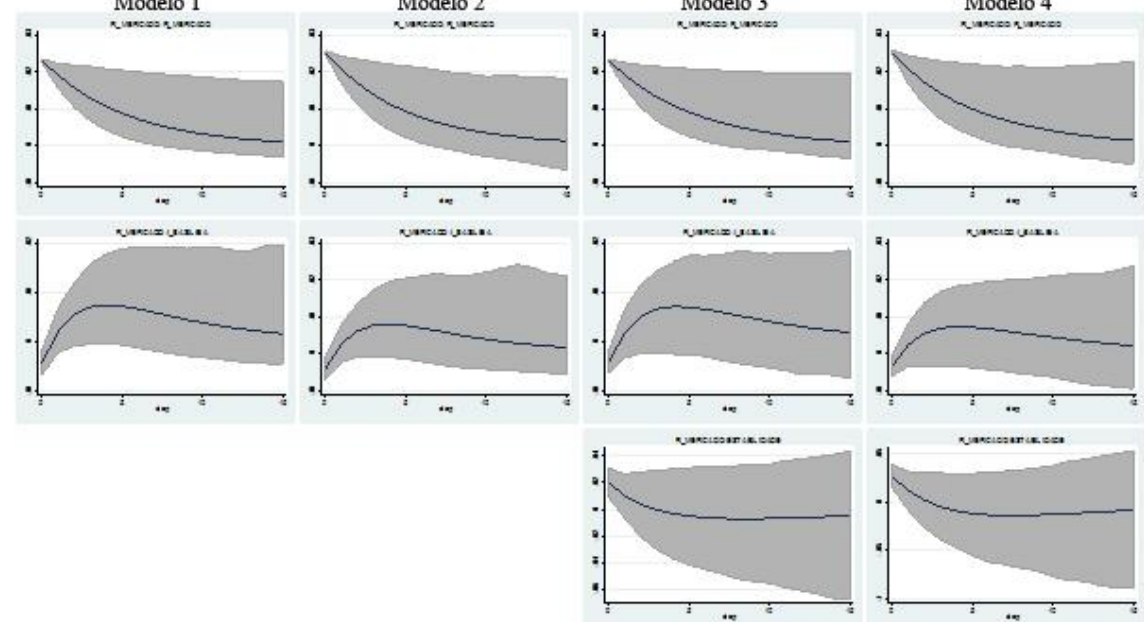

Figura B.4

FIR para um choque no risco de mercado 

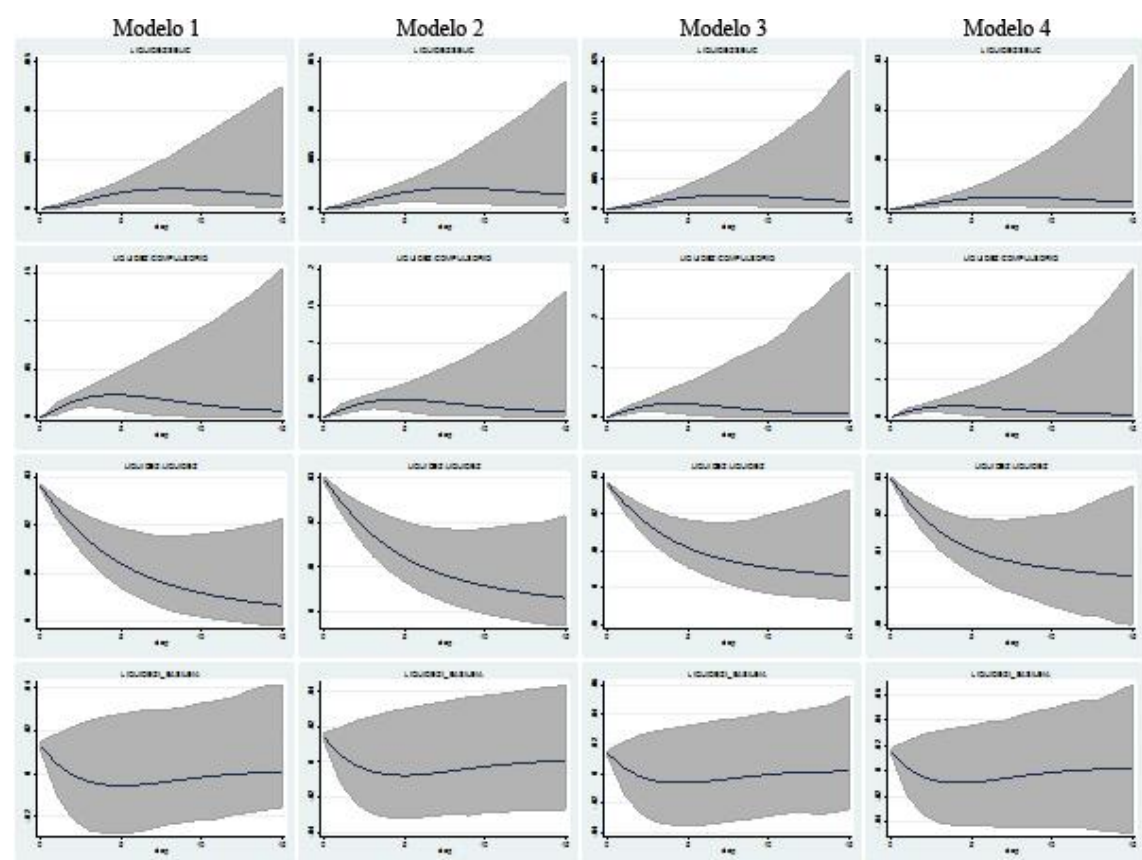

Figura B.5

FIR para um choque de liquidez

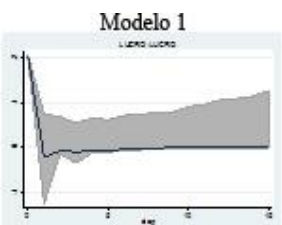

Modelo 2
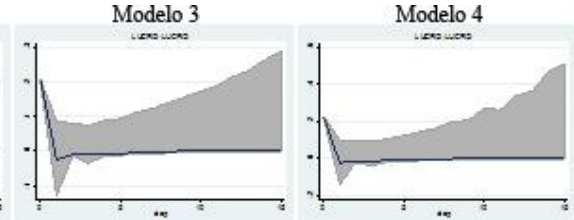

Figura B.6

FIR para um choque no lucro
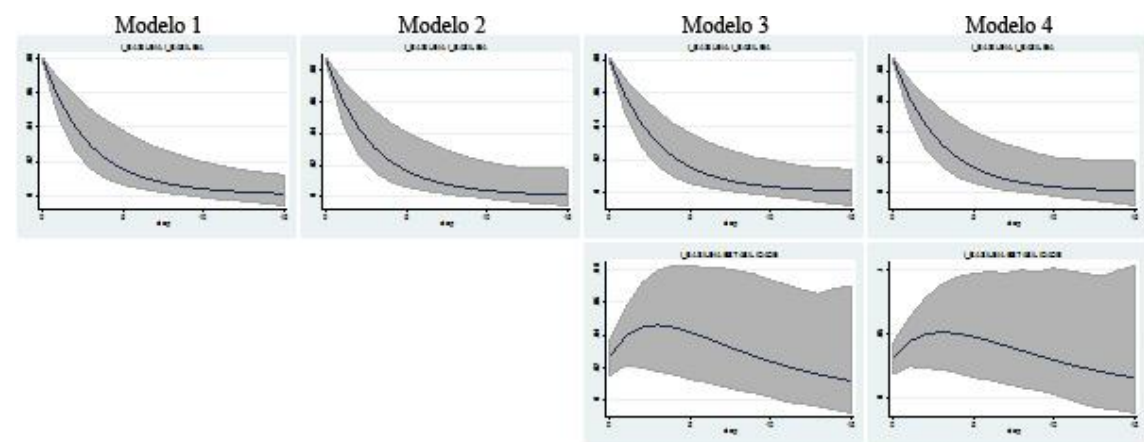

Figura B.7

FIR para um choque no índice de Basiléia 